\title{
Source-sink modifications affect leaf senescence and grain mass in wheat as revealed by proteomic analysis
}

\author{
Xuemei Lv ${ }^{1,2}$, Yan Zhang ${ }^{1,2}$, Yunxiu Zhang ${ }^{2}$, Shoujin Fan ${ }^{2^{*}}$ and Lingan Kong ${ }^{1,2^{*}}$
}

\begin{abstract}
Background: The grain yield of cereals is determined by the synergistic interaction between source activity and sink capacity. However, source-sink interactions are far from being fully understood. Therefore, a field experiment was performed in wheat to investigate the responses of flag leaves and grains to sink/source manipulations.

Results: Half-degraining delayed but partial defoliation enhanced leaf senescence. Sink/source manipulations influenced the content of reactive oxygen species in the flag leaf and the concentration of phytohormones, including cytokinins, indoleacetic 3-acid and jasmonic acid, in the flag leaves (LDef) and grains (GDef) in defoliated plants and flag leaves (LDG) and grain (GDG) in de-grained plants. Isobaric tag for relative and absolute quantitation (iTRAQ)-based quantitative proteomic analysis indicated that at 16 days after manipulation, a total of 97 and 59 differentially expressed proteins (DEPs) from various functional categories were observed in the LDG and LDef groups, respectively, compared with the control, and 115 and 121 DEPs were observed in the GDG and GDef groups, respectively. The gene ontology annotation terms of the DEPs mainly included carbon fixation, hydrogen peroxide catabolic process, chloroplast and cytoplasm, oxidoreductase activity and glutamate synthase activity in the flag leaves of manipulated plants and organonitrogen compound metabolic process, cytoplasm, vacuolar membrane, CoA carboxylase activity, starch synthase activity and nutrient reservoir activity in the grains of manipulated plants. KEGG pathway enrichment analysis revealed that photosynthesis, carbon, nitrogen and pyruvate metabolism and glycolysis/gluconeogenesis were the processes most affected by sink/source manipulations. Sink/source manipulations affected the activities of amylase and proteinases and, ultimately, changed the mass per grain.

Conclusions: Manipulations to change the sink/source ratio affect hormone levels; hydrolytic enzyme activities; metabolism of carbon, nitrogen and other main compounds; stress resistance; and leaf senescence and thus influence grain mass.
\end{abstract}

Keywords: Defoliation, Half-degraining, iTRAQ, Leaf senescence, Photosynthesis, Triticum aestivum

\section{Background}

The grain yield of cereals is determined by the synergistic interaction between source activity and sink capacity. The source restores and supplies reserves to the sink

\footnotetext{
*Correspondence: fanshoujin007@163.com; kongling-an@163.com

${ }^{2}$ College of Life Science, Shandong Normal University, Jinan 250014, China

${ }^{1}$ Crop Research Institute, Shandong Academy of Agricultural Sciences, Jinan 250100, China
}

(developing grains). Sink strength is determined by the number and potential size of grains per stem, depending on the capacity of plants to actively obtain photosynthetic assimilates and reserves in their vegetative organs and accumulate these compounds.

Wheat (Triticum aestivum L.) productivity is generally considered to be sink-limited under favorable conditions, with grain development regulated by the assimilating

(c) The Author(s). 2020 Open Access This article is licensed under a Creative Commons Attribution 4.0 International License, which permits use, sharing, adaptation, distribution and reproduction in any medium or format, as long as you give appropriate credit to the original author(s) and the source, provide a link to the Creative Commons licence, and indicate if changes were made. The images or other third party material in this article are included in the article's Creative Commons licence, unless indicated otherwise in a credit line to the material. If material is not included in the article's Creative Commons licence and your intended use is not permitted by statutory regulation or exceeds the permitted use, you will need to obtain permission directly from the copyright holder. To view a copy of this licence, visit http://creativecommons.org/licenses/by/4.0/ The Creative Commons Public Domain Dedication waiver (http://creativecommons.org/publicdomain/zero/1.0/) applies to the data made available in this article, unless otherwise stated in a credit line to the data. 
capacity but hardly limited by the source [1], because the source generally has the capacity to provide adequate assimilates to developing grains. An increase in the source/sink ratio does not affect the grain mass $[2,3]$. Defoliation in an old germplasm of bread wheat does not cause a source limitation to grain filling [4]. However, inconsistent conclusions have also been observed. Kruk et al. [4] and Beed et al. (2007) [5] reported that grain yields are colimited by both the source and the sink in wheat. Experiments that manipulated assimilate availability during grain filling showed that wheat yields are mainly limited by the sink size [6]. Slafer and Savin reported that the grain yield of wheat is either sink-limited or colimited by both the source and sink but is never source-limited [7]. However, it is difficult to devise direct approaches to determine the relative importance of the source capacity and sink strength in contributing to the grain yield in wheat [8]. Therefore, a better understanding of source-sink interactions would help to propose strategies to improve yield potential using genetic approaches.

A number of phytohormones play vital roles in regulating leaf senescence and grain filling in crops as signaling molecules. Different roles of phytohormones in senescence have been observed: ABA induces senescence, while cytokinins (CTKs) and auxin inhibit senescence [9-11]. The cross-talk among various hormones has been outlined in previous studies. Hormones can be directly involved in the regulation of senescence or can function antagonistically. In addition, interactions of phytohormones with other factors, such as those involved in nitrogen status and sugar signaling, play critical roles in regulating source and sink communication $[12,13]$. Therefore, the regulation of senescence by hormones is a complicated process that requires deeper investigation.

Isobaric tag for relative and absolute quantitation (iTRAQ) is an isobaric labeling method which has been popularly used to identify proteins coming from different sources, providing more reliable quantitative changes than traditional protein analysis [14]. Based on these identified proteins, metabolic pathways can be constructed and protein-protein interaction (PPI) analyses can be performed [15]. Proteomics studies in wheat using iTRAQ have primarily been performed to investigate protein responses to stresses such as drought, reactive oxygen species (ROS) stress and nutrient deficiency to assess the effects of environmental factors on profile characteristics and metabolic pathways $[15,16]$. To date, however, quantitative proteomics studies based on iTRAQ analyses of wheat senescence and grain development when subjected to sink-source manipulations have not been reported.
Modifications of the source-sink relationship by changing the level of competition among developing grains and/or the assimilate availability have previously been used as manipulations after grain setting to understand the effects of the source/sink balance on grain development, aiming at suggesting strategies to increase the grain yield of wheat $[7,17,18]$ and barley (Hordeum vulgare) [19]. Unfortunately, although much effort has been made, we are still far from fully understanding sourcesink interactions [9]. How source-sink interactions can be regulated by cultivation methods and genetic manipulations remains unclear.

The present study was designed to examine the impact of manipulating the source/sink ratio on physiological modifications and protein expression in flag leaves and grains, aiming to determine how leaf senescence and grain mass are regulated by changing the availability of potential assimilates per grain. These results might promote a better understanding of the roles of the sourcesink relationship in grain development and in finding effective avenues, such as genetic modifications during breeding, to further increase the cereal grain yield.

\section{Results}

Values of the normalized difference vegetation index (NDVI), photochemical reflectance index (PRI) and soil and plant analyzer development (SPAD)

The changes of the NDVI, PRI and SPAD values of flag leaves exhibited similar trends (Table 1). These parameters gradually decreased with the progress of grain filling. The PRI values showed greater sensitivity to sinksource modifications than the SPAD and NDVI values. Significant differences in PRI values were observed among the three treatments and growth stages. However, differences in NDVI values were only observed between half-degraining and defoliation at 16 and 24 days

Table 1 Effects of sink-source manipulations on the PRI, NDVI and SPAD values of flag leaves

\begin{tabular}{lllll}
\hline DAM & & PRI & NDVI & SPAD \\
\hline 8 & Control & $0.030 \mathrm{~b}$ & $7.98 \mathrm{ab}$ & $58.77 \mathrm{ab}$ \\
& Half-degraining & $0.032 \mathrm{a}$ & $8.14 \mathrm{a}$ & $59.83 \mathrm{a}$ \\
& Defoliation & $0.028 \mathrm{~b}$ & $7.89 \mathrm{ab}$ & $58.07 \mathrm{ab}$ \\
\multirow{2}{*}{16} & Control & $0.026 \mathrm{~cd}$ & $7.47 \mathrm{~cd}$ & $57.27 \mathrm{bc}$ \\
& Half-degraining & $0.028 \mathrm{bc}$ & $7.74 \mathrm{bc}$ & $58.03 \mathrm{ab}$ \\
& Defoliation & $0.024 \mathrm{e}$ & $7.26 \mathrm{~d}$ & $56.03 \mathrm{c}$ \\
& Control & $0.021 \mathrm{f}$ & $6.21 \mathrm{f}$ & $38.43 \mathrm{e}$ \\
& Half-degraining & $0.025 \mathrm{de}$ & $6.57 \mathrm{e}$ & $40.73 \mathrm{~d}$ \\
& Defoliation & $0.018 \mathrm{~g}$ & $6.14 \mathrm{f}$ & $33.17 \mathrm{f}$ \\
\hline
\end{tabular}

PRI, Photochemical Reflectance Index; NDVI, Normalized Difference Vegetation Index; SPAD, Soil and Plant Analyzer Development. Data were obtained from three replicates. Means followed by the same letters within a column are not significantly different according to Duncan's multiple range test $(p<0.05)$ 
after manipulation (DAM). At 16 DAM, significant differences in SPAD values were only observed between half-degraining and defoliation. At 24 DAM, the highest level was observed in the half-degrained flag leaf (LDG) group, followed by a significant decrease in the flag leaves in control plants (LC) group and a further decrease in the defoliated flag leaf (LDef) group (Table 1).

\section{Chlorophyll fluorescence}

Values of the maximum PSII quantum yield $(F v / F m)$ and the effective PSII quantum yield $\left(\Phi_{\text {PSII }}\right)$ of flag leaves were measured from 9:00-11:00 a.m. These values after the half-degraining treatment were higher than those of the intact control at 16 and 24 DAM. Defoliation significantly decreased the $F v / F m$ value at 16 and 24 DAM

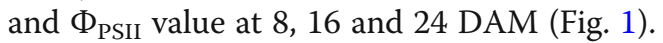

\section{Chloroplast structure}

An obvious difference in the cell ultrastructure of leaf tissues was observed under a transmission electron

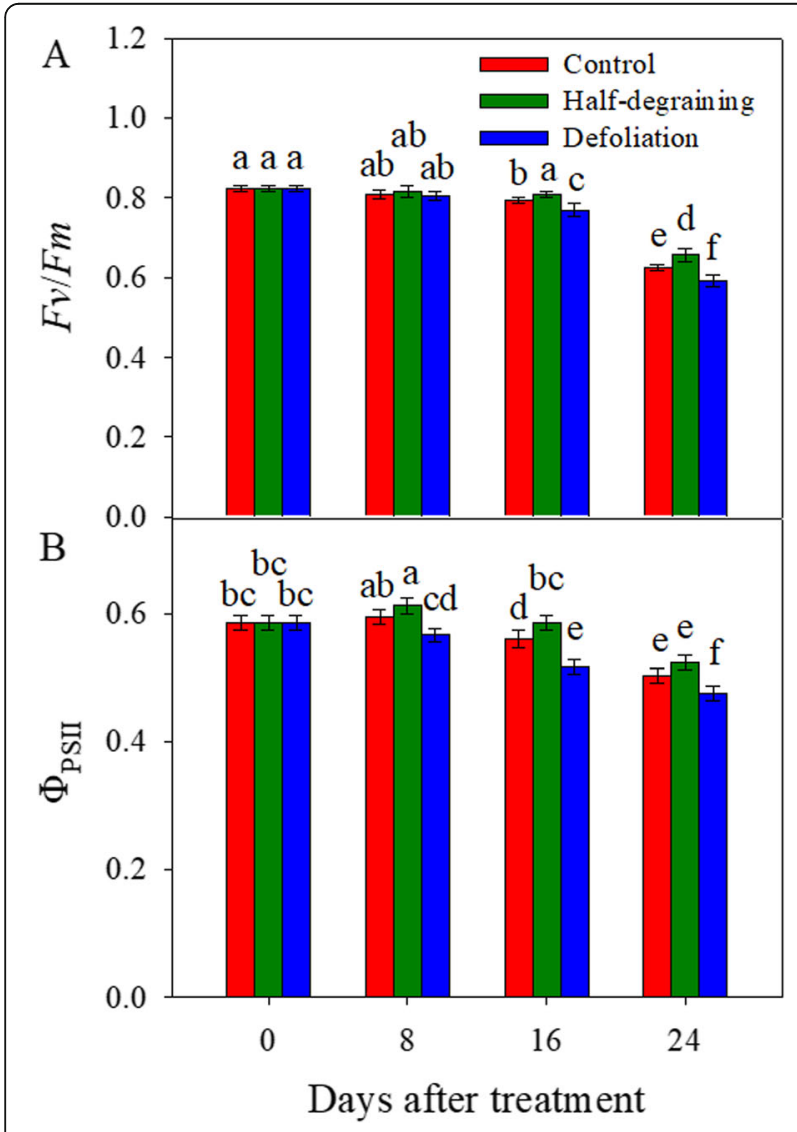

Fig. 1 Effects of sink/source manipulation on the fluorescence parameters of flag leaves in wheat. Fv/Fm: maximal efficiency of the

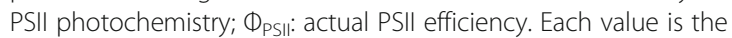
mean \pm standard deviation (SD) from at least six leaves. Columns labeled with different letters significantly differ at $p<0.05$ according to Duncan's multiple range test microscope at 16 DAM (Fig. 2). The chloroplasts in leaf tissues were spherical after all three treatments. In LDG cells (Fig. 2a), the chloroplasts contained a larger number of thylakoids and the matrix of the chloroplasts was still dense compared with those of the control (Fig. 2b) and defoliation treatment groups (Fig. 2c). In LDef cells, numerous small vesicles or membrane-like fragments were observed in the cytoplasm (Fig. 2c). The membranes constituting the thylakoids were less distinct and seriously disrupted in LDef cells compared to those in control cells. Moreover, the structure of the thylakoids in LDef cells was characterized by the loss of the parallel arrangement of the grana lamellae in some chloroplasts, and some of the thylakoids in these cells became swollen. In LDef cells, the number of chloroplasts was $9.80 \pm$ 0.80 per cell section, significantly lower than $12.60 \pm 1.39$ and $13.67 \pm 1.40$ per cell section in LC and LDG cells (Fig. 2c), respectively.

\section{Antioxidant enzyme activity of flag leaf}

At 8 DAM, no significant difference in superoxide dismutase (SOD) activity was observed among the LDG, LDef and LC groups. At 16 and 24 DAM, halfdegraining significantly decreased SOD activity compared with that of the control $(p<0.05)$. However, defoliation increased SOD activity at $16(p>0.05)$ and 24 $(p<0.05)$ DAM (Fig. 3a). Peroxidase (POD) activity exhibited an almost identical changing trend as SOD activity during the period from 8 to 24 DAM (Fig. 3b). At 8 and 24 DAM, half-degraining significantly decreased catalase (CAT) activity with respect to that of the control $(p<0.05)$. The defoliation treatment decreased CAT activity at 8 DAM $(p<0.05)$ but caused sharp increases in activity thereafter and thus induced a significant enhancement of CAT activity 24 DAM $(p<0.05)$ (Fig. 3c). Despite the higher activities of these enzymes, especially at 24 DAM, the ROS content was still higher in the flag leaves of defoliated plants compared to that in the flag leaves of the control. However, no difference in ROS content was observed in flag leaves between halfdegraining and intact plants (Fig. 3d).

\section{Effects of sink-source manipulations on endogenous hormones in flag leaves and grains}

The leaf/grain ratio of endogenous hormone concentration was used to evaluate the source strength and sink capacity balance. The total concentration of zeatin + zeatin riboside + kinetin was used to evaluate the changes in CTKs after manipulations. Compared with the control plants, the half-degraining treatments significantly increased and defoliation decreased the leaf/grain ratio of the CTK concentration at the three time points $(p<0.05)$ (Table 2). At 8 and 16 DAM, no significant difference in the leaf/grain ratio of indoleacetic 3-acid 


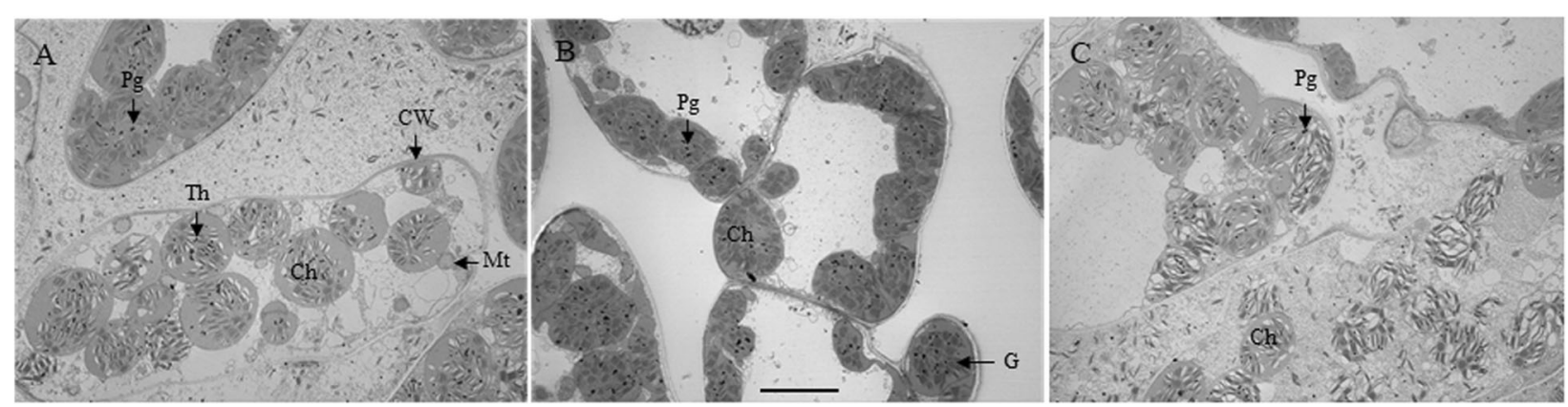

Fig. 2 Transmission electron micrographs showing the ultrastructure of the chloroplast at 16 DAM in flag leaves of the control (a), half-degraining (b) and defoliation (c) treatment groups. The images are representative of five biological replicates. Bars: 5 um; Ch, chloroplast; CW, cell wall; G, granum; Mt, mitochondrion; Pg, plastoglobuli; Th, thylakoid

(IAA) concentration was observed between the degraining treatment and control. For defoliation, this treatment significantly decreased the leaf/grain ratio of IAA $(p<0.05)$ (Table 2). Half-degraining did not affect the leaf/grain ratio of jasmonic acid (JA) concentration, whereas defoliation significantly decreased this ratio throughout the experimental period $(p<0.05)$ (Table 2).

\section{Proteome profiles of flag leaves and grains under sink- source modifications}

To investigate the proteome alterations of wheat flag leaves and grains due to different sink-source modifications, iTRAQ-based quantitative proteomics analysis was conducted. A total of 2821 proteins in flag leaves and 2467 proteins in grains were reliably identified at a global false-discovery rate (FDR) of $1 \%$. In the LDG group, 97 proteins were assigned as differentially expressed compared with those in the intact control, including 80 increased and 17 decreased proteins. In the LDef group, 59 proteins were assigned as differentially expressed compared with those in the LC group, including 54 increased proteins and 5 decreased proteins. In the remaining grains of the half-degrained spike (GDG) group, 115 proteins were assigned as differentially expressed compared with those in the grain in control plants (GC) group, including 43 increased proteins and 72 decreased proteins. In the defoliated grain (GDef) group, 121 proteins were assigned as differentially expressed compared with those in the GC group, including 47 increased proteins and 74 decreased proteins (Fig. 4; Table S1).

\section{Gene ontology (GO) analysis}

To illustrate the major responsive processes in flag leaves and grains, enrichment analysis was performed to assess the GO annotations. Differentially expressed proteins (DEPs) were clustered in the biological process (BP), cell component (CC), and molecular function (MF) categories according to GO analysis, and the top $20 \mathrm{GO}$ terms are shown in Fig. 5.

$\mathrm{BP}$ analysis revealed that the DEPs identified in the comparison of the LDG with LC groups were mainly classified into carbon fixation, oxidation-reduction process, organonitrogen compound metabolic process, carbohydrate biosynthetic process, starch biosynthetic process, etc. According to MF analysis, the DEPs were classified into carbon-carbon lyase activity, oxidoreductase activity, structural constituent of ribosome, ferredoxin:thioredoxin reductase activity, ferredoxindependent glutamate synthase activity, glutamine hydrolysing activity, betaine-aldehyde dehydrogenase activity, etc. According to $\mathrm{CC}$ analysis, half-degraining mainly affected the chloroplast, plastid, cytoplasmic part, cytoplasm and intracellular organelles (Fig. 5a; Table S2).

In comparison of the LDef and LC groups, BP analysis revealed that the DEPs identified were mainly classified into organophosphate metabolic process, glyceraldehyde-3-phosphate metabolic process, glucose 6-phosphate metabolic process, photosynthesis, carbohydrate derivative metabolic process, etc. According to MF analysis, responses to defoliation mainly included the activities of electron carrier, proton-transporting ATPase, hydrogen-exporting ATPase, hydrogen ion transmembrane transporter, iron-sulfur cluster binding, tocopherol cyclase and glutaminyl-tRNA synthase (glutaminehydrolyzing). Defoliation mainly affected chloroplasts, plastids, thylakoid membranes, chloroplast envelopes, organelle subcompartments and photosystem II (Fig. 5b; Table S2).

In comparison of the GDG and GC groups, BP analysis revealed that the proteins identified were mainly classified into organonitrogen compound metabolic process, cell wall macromolecule catabolic, amino sugar catabolic, defense response, aminoglycan metabolic, amino sugar metabolic, protein folding in endoplasmic reticulum (ER) and nucleoside metabolic processes. In comparison of the GDef/GC groups, the majority of 


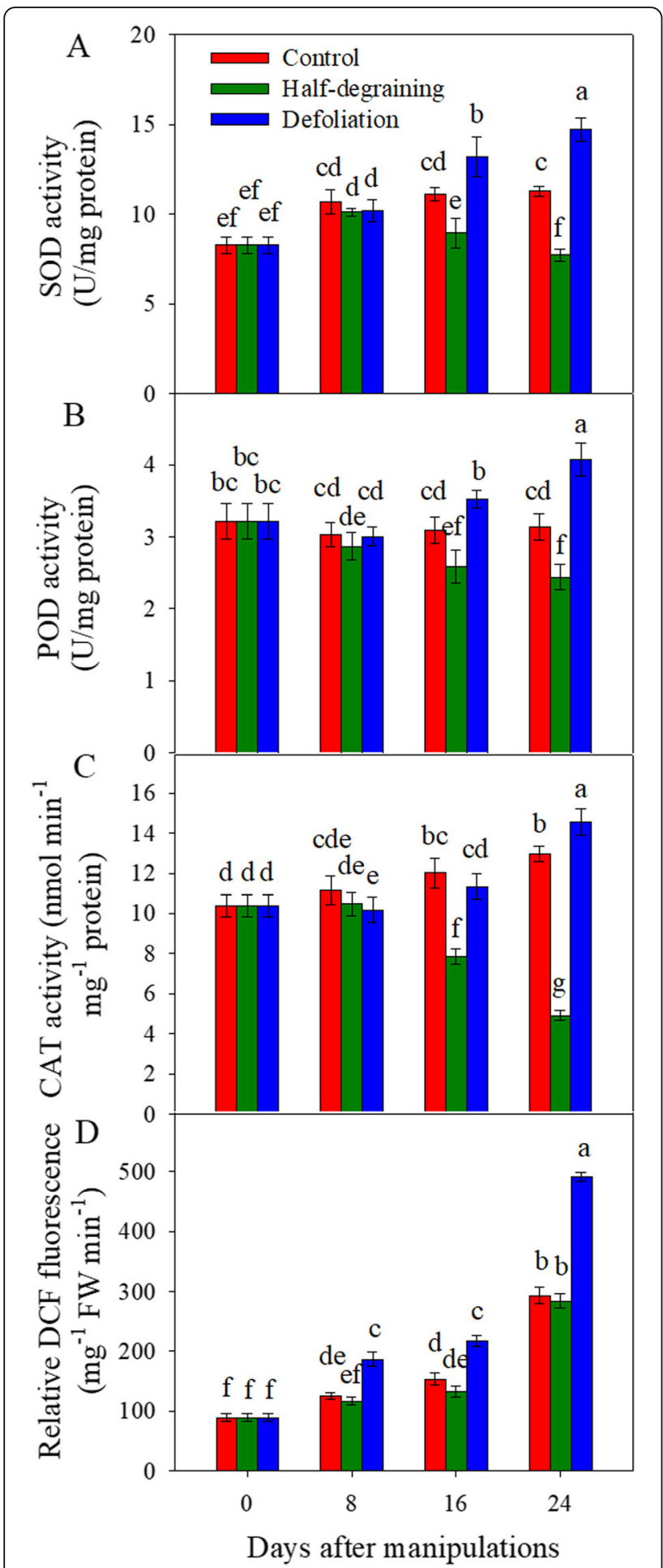

Fig. 3 Effects of sink-source manipulations on antioxidant enzyme activities and the relative DCFH-DA fluorescence intensity of wheat flag leaves. The results are the mean \pm SD

identified proteins were classified into the activities of CoA carboxylase, ligase, forming carbon-carbon bonds, biotin carboxylase, methylcrotonoyl-CoA carboxylase,
Table 2 Effects of sink and source manipulations on the phytohormone concentration leaf/grain ratio in wheat. Data were obtained from three replicates

\begin{tabular}{lllll}
\hline DAM & Treatment & CTKs & IAA & JA \\
\hline 8 & Control & $0.75 b c$ & $0.76 a$ & $2.00 \mathrm{a}$ \\
& Half-degraining & $0.99 \mathrm{a}$ & $0.76 \mathrm{a}$ & $1.65 \mathrm{~b}$ \\
& Defoliation & $0.57 \mathrm{~d}$ & $0.61 \mathrm{~cd}$ & $0.84 \mathrm{~d}$ \\
\multirow{2}{*}{16} & Control & $0.70 \mathrm{c}$ & $0.75 \mathrm{a}$ & $1.65 \mathrm{~b}$ \\
& Half-degraining & $0.78 \mathrm{~b}$ & $0.72 \mathrm{ab}$ & $1.58 \mathrm{~b}$ \\
& Defoliation & $0.52 \mathrm{~d}$ & $0.38 \mathrm{e}$ & $0.65 \mathrm{~d}$ \\
& Control & $0.82 \mathrm{~b}$ & $0.66 \mathrm{bc}$ & $1.15 \mathrm{c}$ \\
& Half-degraining & $0.95 \mathrm{a}$ & $0.56 \mathrm{~d}$ & $1.07 \mathrm{c}$ \\
& Defoliation & $0.70 \mathrm{c}$ & $0.30 \mathrm{f}$ & $0.71 \mathrm{de}$ \\
\hline
\end{tabular}

DAM: Days after manipulation. Means followed by the same letters within a column are not significantly different according to Duncan's multiple range test $(p<0.05)$

acetyl-CoA carboxylase, starch synthase, etc. According to $\mathrm{CC}$ analysis, half-degraining mainly affected the cytoplasm, cytoplasmic parts, vacuolar membrane, the mitochondria, intracellular parts and chloroplast thylakoids (Fig. 5c; Table S2).

According to BP analysis, grain responses to defoliation mainly included processes of organonitrogen compound metabolism, protein glutathionylation, protein folding in the ER, oxidoreduction coenzyme metabolism, L-proline biosynthesis, glucose 6-phosphate metabolism, endosperm development and others. According to MF analysis, responses to defoliation mainly included the activities of glutamate 5-kinase, glucokinase, glutamate-5semialdehyde dehydrogenase, unfolded protein binding, glucose-6-phosphate dehydrogenase, sucrose synthase, structural constituent of ribosome, amino acid kinase, pyruvate kinase, protein domain specific binding and

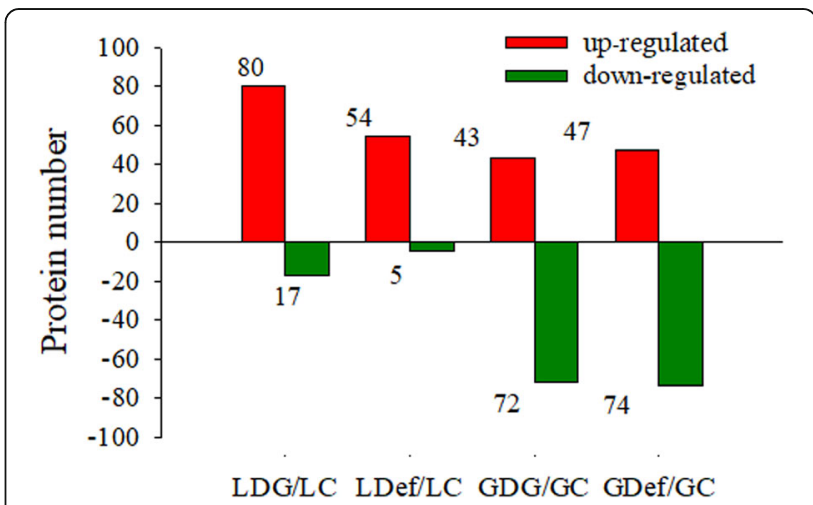

Fig. 4 Number of differentially expressed proteins (DEPS) of the different groups. Data were obtained from two biological replicates. GC, grains in control plants; GDef, grains in defoliated plants; GDG, grains in de-grained plants; LC, leaves in control plants; LDef, leaves in defoliated plants; LDG, leaves in the de-grained plants 


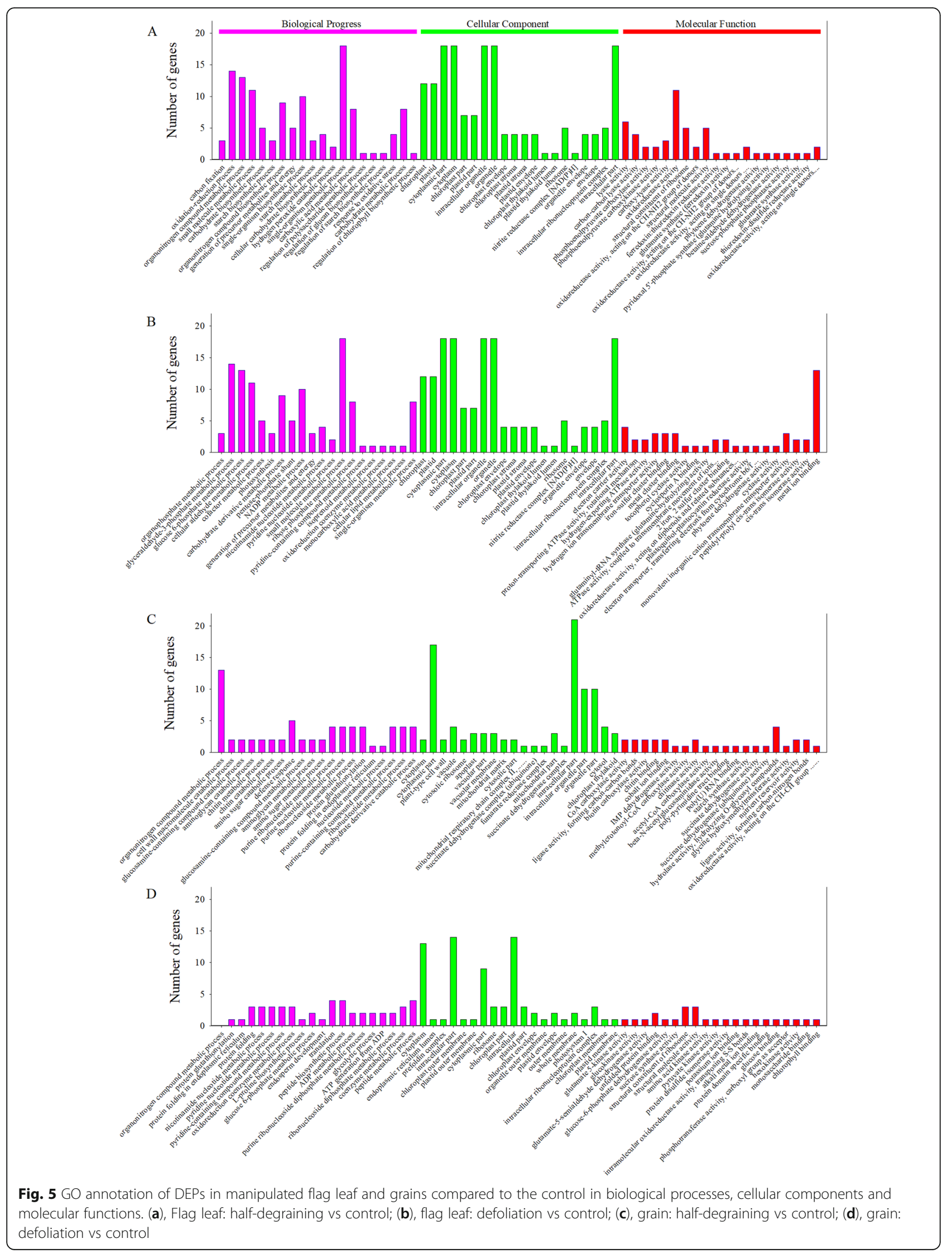


chlorophyll binding. Defoliation mainly affected the cytoplasm, ER lumen, cytoplasmic parts, ribosome, chloroplast parts and intracellular ribonucleoprotein complex (Fig. 5d; Table S2).

\section{Kyoto encyclopedia of genes and genomes (KEGG) pathway analysis}

To understand the major responses of cellular processes to sink-source modifications in flag leaves and grains, the KEGG pathway database was used based on the large-scale molecular dataset. According to pathway enrichment analysis, the DEPs in the LDG group were significantly enriched in linoleic acid metabolism and $\alpha$ linolenic acid metabolism, carbon fixation in photosynthetic organisms, nitrogen metabolism, carbon metabolism and vitamin $\mathrm{B}_{6}$ metabolism. The DEPs in the LDef group were significantly enriched in photosynthesis, carbon metabolism, metabolic pathways, oxidative phosphorylation, glyoxylate and dicarboxylate and metabolism (Fig. 6a). In comparison of the GDG group to the GC group, the DEPs were significantly enriched in four pathways in the KEGG database: carbon metabolism was the most represented pathway, followed by the citrate cycle (TCA cycle); glycine, serine and threonine metabolism; and glyoxylate and dicarboxylate metabolism. Most proteins in these pathways were decreased. In comparison of the GDef/GC groups, the DEPs were only enriched in two pathways, including protein processing in the ER and carbon metabolism (Fig. 6b). Taken together, the enrichment analyses based on proteomics data suggested that photosynthesis, carbon metabolism, and nitrogen/amino acid metabolism were the processes most responsive to sink/source manipulation.

\section{Enzyme activities}

During the experiment, the activities of neutral proteinase (NP), alkaline proteinase (AKP) and acid proteinase (ACP) (Fig. 7) in the flag leaves of intact plants remained relatively constant. Degraining decreased the NP (Fig. 7a), AKP (Fig. 7b) and ACP (Fig. 7c) activities at 8, 16 and 24 DAM compared with those in intact plants. Defoliation decreased NP activity at 8, 16 and 24 DAM but significantly increased AKP activity at 8, 16 and 24 DAM and ACP activity at 16 and 24 DAM.

Overall, the amylase activity in flag leaves was higher from 8 to 24 DAM than that at 0 DAM and remained constant from 8 to 24 DAM. From 8 to 24 DAM, defoliation significantly increased amylase activity compared with that of the control. No difference in amylase activity was observed at 8 and 16 DAM. At 24 DAM, the half-degraining treatment significantly decreased amylase activity (Fig. 7d).
Grain mass responses to source and sink manipulations The removal of spikelets on one side of spikes did not halve the grain number per spike (Table 3). Halfdegraining increased the grain number per half-spike by $10.49 \%(p<0.05)$ and the single grain mass by $8.54 \%$ $(p<0.05)$ compared with those of the control. As a consequence, half-degraining increased the grain mass per half-spike by $19.92 \%$. Defoliation reduced the grain number per half-spike by $16.37 \%(p<0.05)$. Grain mass also significantly responded to defoliation, which caused a reduction in grain mass per half-spike of $19.64 \%(p<0.05)$. These data suggest that half-degraining reduces kernel abortion; hence, the number of grains per half spike after half-degraining was the highest of all treatments, and the inverse was true for after the defoliation treatment.

\section{Discussion}

The source/sink interaction modulates leaf senescence, photosynthetic efficiency [20] and grain filling capacity, thus determining the yield of cereals $[8,21]$. A strong source with sufficient reserves is necessary for grain filling, and a high sink capability promotes reserve remobilization from the source to the sink [22, 23]. In the present study, the values of NDVI, PRI and SPAD and chlorophyll fluorescence were determined from a single leaf, and we observed that half-degraining increased and defoliation decreased the levels of these indices compared to those in the intact control (Table 1; Fig. 1). Ultrastructural observations of flag leaf mesophyll cells at 16 DAM indicated that the state of chloroplasts retained better after half-degraining (Fig. 2b) but was inferior after defoliation (Fig. 2c). NDVI, PRI and SPAD are the most frequently used spectral indices and are associated with the chlorophyll content and leaf senescence in higher plants [24]. Chlorophyll fluorescence and chlorophyll degradation are also widely used as typical indicators of the progression of senescence and photosynthesis [19, 25-27]. Higher values of these indices are closely associated with grain yield [28]. Therefore, the evidence presented in the present study suggests that halfdegraining may cause later leaf senescence, but defoliation may cause earlier leaf senescence.

It is well known that plant senescence is accelerated by ROS, while antioxidant enzymes play important roles in scavenging excess ROS and reduce detrimental effects of ROS on the cellular membrane [29, 30]. In wheat, the competence of the antioxidant defense system contributes to delayed senescence [31]. In the present study, the ROS content was higher in the LDef group than in the LC group, even though defoliation significantly increased the activities of SOD, POD and CAT, especially at 24 DAM, suggesting that increased levels of antioxidant enzymes may be a response to increased levels of ROS. In the DEPs identified using iTRAQ analysis, SOD 

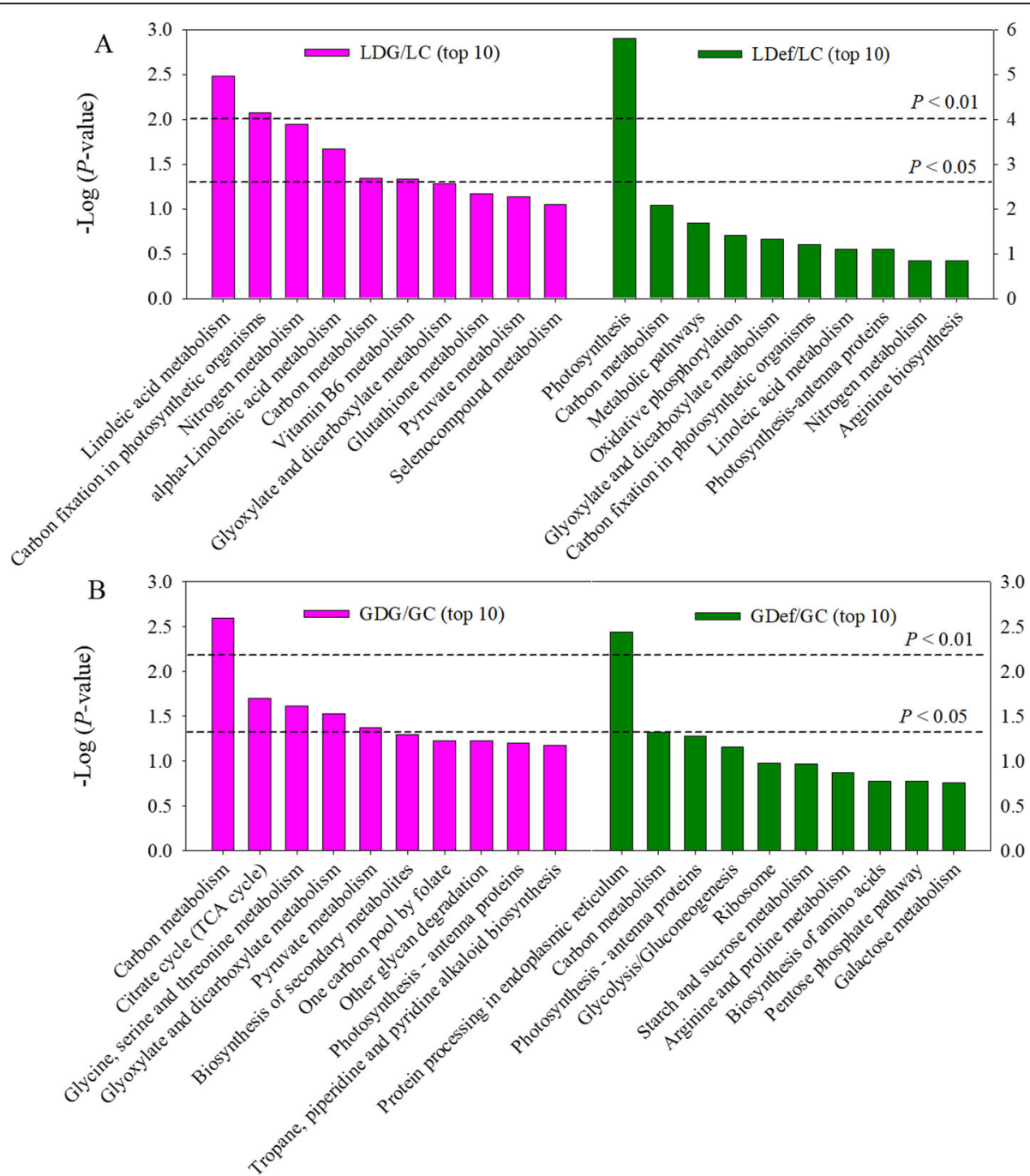

Fig. 6 Most significant associated KEGG pathways of DEPs for LDG/LC (flag leaves of half-degrained group compared with control) and LDef/LC (flag leaves of defoliated group compared with control) (a) and GDG/GC (grains of half-degrained group compared with control) and GDef/GC (grains defoliated group compared with control) (b)

(fragment) was upregulated in the LDef group at 16 DAM (Table S1). These results suggest that partial source removal may induce more active physiological responses and thus cause a burst of ROS and membrane oxidation, which in turn, result in premature senility of wheat plants. The increases in these antioxidant enzyme activities may be a strategy to protect plants from more serious damage, to partially relieve early senescence and to attempt to increase the active grain-filling period and grain mass. In contrast, the activities of SOD, POD and CAT decreased in the LDG group, but the ROS content also slightly decreased (Fig. 3; Table S1 for POD), indicating that half-degraining may impose a lower "burden" on flag leaves, resulting in lower ROS production.

Plant hormones and associated hormonal crosstalk are significantly related to modifications of the source/sink relationship, sink capacity, grain-filling rate [32-34], membrane stability, foliar senescence and photosynthetic efficiency, possibly by acting as signals to scavenge ROS or prevent ROS formation [35-37].

Cytokinins are the most significant phytohormones that regulate the initiation and timing of leaf senescence $[10,38,39]$ and are closely associated with the progress of leaf senescence in the stay-green mutant tasg1 of wheat [31] and in the stay-green phenotype of maize (Zea mays) [40]. The grain CTK contents are positively associated with the maximum grain mass [35, 41, 42]. In main cereal crops including wheat, a higher CTK concentration is found in the endosperm of grains and functions during cell division there at the early stages of grain development, which, in combination with the functions of auxin, are positively and significantly correlated 


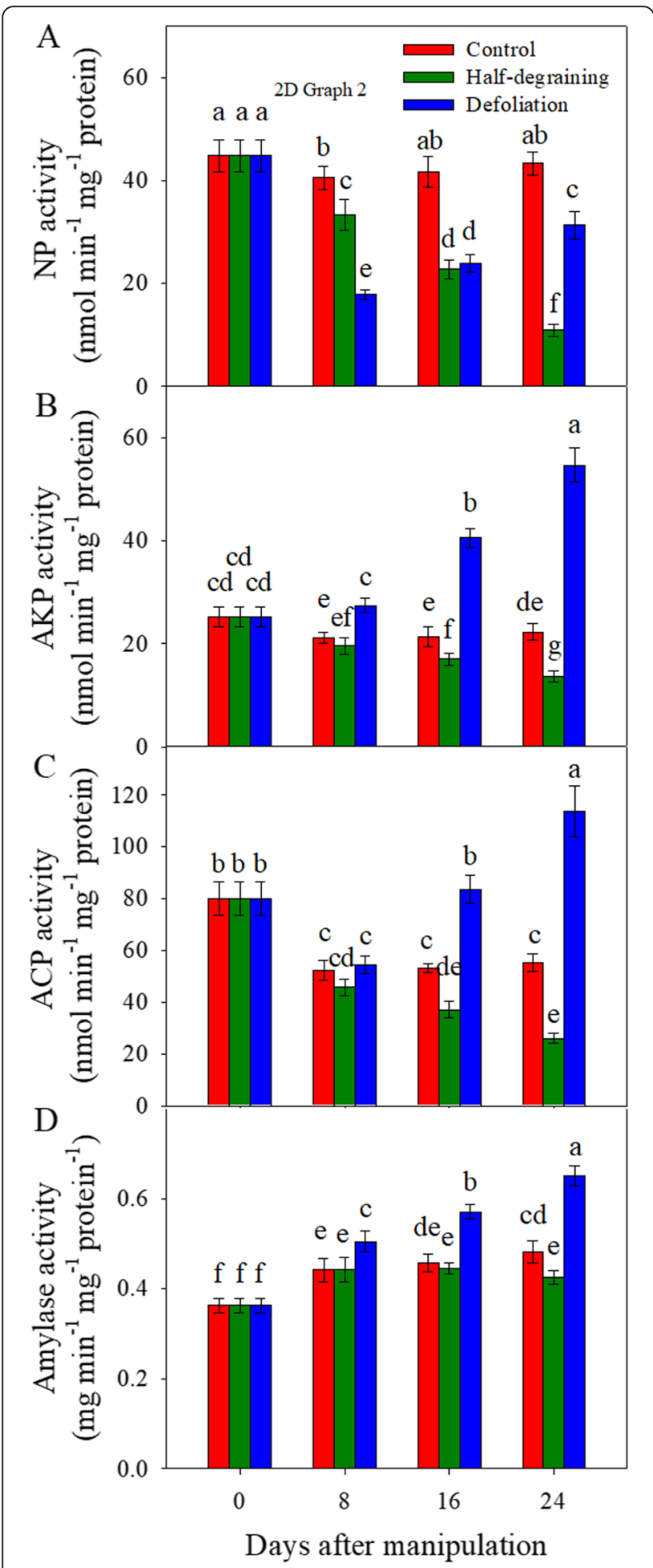

Fig. 7 Comparison of the activities of neutral proteinase (a), alkaline proteinase (b), acid proteinase (c) and amylase (d) in flag leaves from the half-degraining, defoliation and control groups. Each value represents the mean \pm SD from three independent samples. Columns labeled with different letters are significantly different at $p<0.05$ according to Duncan's test for multiple comparisons with the rate of both cell division and grain filling [11, $34,39,42-45]$ due to the enhanced sink strength [46, 47].

The grain IAA concentration rapidly increases in maize at early grain filling [48], thus creating an "attractive power" and leading to an increase in the CTK concentration in grains $[49,50]$, which is associated with an increase in assimilate transport to developing grains [48]. In addition, auxin is linked with an enhanced sink capacity, resulting in increases in nutrient assimilation source nutrient remobilization, cell enlargement and the grain-filling rate [51, 52].

In our study, defoliation decreased the leaf/grain ratio CTK and IAA concentrations (Table 2). Based on results from current and previous studies, we postulate that higher source competition due to defoliation relatively stimulates hormone biosynthesis in grains, thereby increasing the sink strength and enhancing their potential to absorb more reserves from the limited source. Meanwhile, relatively lower levels of CTKs and IAA in defoliated flag leaves promote the degradation of large molecules for grain filling, which causes early senescence, as demonstrated by the ultrastructural observations and measurements of the vegetation indices (Table 1; Fig. 2). This view is highly consistent with the findings that indicate that in cultivars with larger sink ratios, there is greater competition for the source photosynthate supply to meet grain filling, leading to premature senescence [21]. Furthermore, the data presented in the present study suggest that the leaf /grain ratio of the CTK and IAA concentration may play a dominant role in regulating leaf senescence in wheat.

Half-degraining increased the leaf/grain ratio of CTK concentration (Table 2). Based on these results and as discussed above, we suggest that the relatively high source strength due to half-degraining and thus the lower competitive pressure for source reserves cause a higher leaf/grain ratio of CTKs and a slower remobilization of leaf reserves, which contribute to delayed leaf senescence.

CTKs and JA are the major hormones that have antagonistic signaling effects on plant senescence [13]. The accumulation of ROS and JA leads to early leaf senescence and a low photosynthesis efficiency [53]. Specific inhibition of JA biosynthesis in the leaf results in an increase in the grain yield of rice [54]. In our study, we observed that half-degraining decreased the leaf/grain ratio of JA concentration at 8 DAM and defoliation decreased this ratio during the experimental period (Table 2). Considering the response of JA to source manipulation, we hypothesize that the lower leaf/grain ratio of JA may have contributed to avoid premature leaf senescence in defoliated plants. 
Table 3 Effects of half-degraining and defoliation on the grain number per half-spike, single grain mass and number of spikelets and grain mass per half-spike

\begin{tabular}{llll}
\hline & Grain number half-spike ${ }^{-1}$ & Single grain mass $(\mathrm{mg})$ & Grain mass half-spike $^{-1}(\mathrm{mg})$ \\
\hline Control & $17.35 \mathrm{~b}$ & $44.27 \mathrm{~b}$ & $768.08 \mathrm{~b}$ \\
Half-degraining & $19.17 \mathrm{a}$ & $48.05 \mathrm{a}$ & $921.12 \mathrm{a}$ \\
Defoliation & $14.51 \mathrm{c}$ & $42.54 \mathrm{~b}$ & $617.26 \mathrm{C}$ \\
\hline
\end{tabular}

Data were obtained from three replicates. Means followed by the same letters within a column are not significantly different according to Duncan's multiple range test $(p<0.05)$

Leaf senescence is associated with fundamental changes in the proteome. In the present study, comparative proteome analysis based on iTRAQ was performed to identify the critical candidate factors involved in leaf senescence and grain filling. The GO terms within the $\mathrm{BP}, \mathrm{MF}$ and CC categories are shown in Fig. 5. KEGG pathway enrichment analysis of these genes was also performed (Fig. 6).

The chloroplast is the central organelle that produces ROS, whereas accumulation of ROS may cause oxidative damage and inhibit photosynthesis [55]. Ferredoxin: thioredoxin reductase is required for chloroplast development in Arabidopsis thaliana [56] and acts as a component of antioxidative defense systems [57]. The destruction of the oxidation-reduction system causes a burst of ROS, such as superoxide $\left(\mathrm{O}_{2}{ }^{\cdot-}\right)$ and hydrogen peroxide $\left(\mathrm{H}_{2} \mathrm{O}_{2}\right)$, leading to early leaf senescence [58, 59]. Glutathione is recycled through the oxidation/reduction process and is thus involved in oxidative stress; its metabolism plays an important role in maintaining the redox balance, eliminating oxidative damage [60]. Phytoene dehydrogenase is associated with the biosynthetic pathway of carotenoid, which serves as a membrane antioxidant [61]. In comparison between the LDG and LC groups, ferredoxin:thioredoxin reductase was clustered in MF and was upregulated in the LDG group. The most prevalent GO terms for BP were involved in ROS metabolic processes, including oxidation-reduction process, response to oxidative stress, $\mathrm{H}_{2} \mathrm{O}_{2}$ metabolic process and $\mathrm{O}_{2}{ }^{--}$removal (Table $\mathrm{S} 1$ ). In these processes, the homeostasis of the oxidation-reduction process was most strongly enhanced in the LDG group, as judged by the PAS_Zscore (Table S2). According to MF analysis, the activities of phytoene dehydrogenase and several kinds of oxidoreductases were significantly affected, and glutathione metabolism was identified in the top 10 KEGG pathways (Fig. 5a). Thylakoid-bound ascorbate peroxidase (APX) (fragment) and betaine aldehyde dehydrogenase (BADH; an important enzyme for betaine biosynthesis) were upregulated (Table S1) and involved in many pathways (Fig. S1). Both APX and betaine function as ROS scavengers [62]. These results imply that half-degraining may enhance the antioxidant ability of leaves by promoting ROS scavenging activities and may, at least, partially contribute to the delayed leaf senescence (Table 1; Fig. 2).

KEGG pathway analysis of the LDG/LC groups suggested that the DEPs were mainly involved in nitrogen and carbon metabolism. Correspondingly, MFs, including the glutamate synthase, ferredoxin-dependent glutamate synthase (Fd-GOGAT; EC 1.4. 7.1) and pyridoxal 5 '-phosphate synthase (glutamine hydrolyzing) activities and carbon metabolism (Fig. 5a; Table S2), were affected. BP analysis showed that these processes were upregulated, indicating that nitrogen and carbon metabolism may be enhanced in the LDG group. Indeed, according to $\mathrm{CC}$ analysis, the categories that play important roles in protein biosynthesis, such as the cytosolic ribosome and ribosome, were highly represented in the LDG group (Fig. 5a; Table S2). Accordingly, DEPs such as $60 \mathrm{~S}$ ribosomal and $40 \mathrm{~S}$ ribosomal proteins were upregulated (Table S1).

In comparison between the LDG and LC groups, the DEPs related to photosynthesis and generation of precursor metabolites and energy were upregulated (Table S1) and showed a significant interaction with carbon fixation in photosynthetic organisms (Fig. S1B). MFs, such as the activities of phosphoenolpyruvate carboxykinase, and sucrose-phosphate phosphatase, were affected (Table S1). Most importantly, sucrose phosphate phosphatase is associated with source activity, enhances the transport of its resulting product sucrose from leaf into the sink [63] and affects the progress of leaf senescence in wheat [64].

In the GDG group, amine oxidase, which catalyzes the reaction to produce $\mathrm{H}_{2} \mathrm{O}_{2}$ [65], was downregulated compared with that in the GC group, while $\mathrm{Cu}-\mathrm{Zn} \mathrm{SOD}$ and dehydroascorbate reductase (DHAR) were upregulated (Table S1). SOD is an important antioxidant enzyme, and DHAR reduces the level of leaf ROS through its recycling of ascorbic acid, a major antioxidant in plants and as a consequence, influences the rate of leaf senescence and photosynthetic activity [29, 30]. Accordingly, GO analysis showed that the primary amine oxidase and oxidoreductase activities were affected. Protein glutathionylation, a mechanism for redox regulation and signaling [66], was upregulated (Table S2). These changes suggest that the remaining grains may have a 
higher ability to scavenge ROS in half-degrained plants with higher source/sink ratio.

Protein disulfide isomerases (PDIs) are enzymes found primarily in the ER in eukaryotes and play a vital role in protein folding. The levels of PDIs are associated with the activity of protein biosynthesis [67-69] and abiotic stress resistance [68]. In the present study, the levels of PDIs were upregulated in the GDG group (Table S1), and the $60 \mathrm{~S}$ ribosomal protein L29, 40S ribosomal protein S12 and eukaryotic translation initiation factor 4B1 were also upregulated (Table S1). These changes indicate de-graining may affect protein synthesis in the grains of GDG group.

Photosynthetic processes, including photosynthesis and the light reaction, light harvesting and the dark reaction, were also significantly upregulated; in addition, plastocyanin and $r b c L$ gene products (fragments) were upregulated in the GDG group, indicating a possible higher use efficiency of light. The $r b c L$ gene is involved in carbon, glyoxylate and dicarboxylate metabolism [70]. These changes indicate that half-degraining affect metabolism of carbon, glyoxylate and dicarboxylate through the expression of $r b c L$ gene as shown in Fig. S1C.

In plants, acetyl-CoA carboxylase catalyzes the first committed step of de novo fatty acid biosynthesis via the carboxylation of acetyl-CoA to malonyl-CoA [69, 71, 72]. In the present study, acetyl-CoA carboxylase, plastid acetyl-CoA carboxylase (fragment) and acetyl-coenzyme A carboxylase (fragment) were downregulated in the GDG group; the activities of CoA carboxylase, acetylCoA carboxylase and biotin carboxylase were also affected. Plastid acetyl-CoA carboxylase showed interactions with many other DEPs (Fig. S1C). These results indicate that fatty acid biosynthesis may be affected in the GDG group.

In the analysis of the MF category for the GDG/GC group, processes involved in succinate dehydrogenase (ubiquinone) activity were identified (Fig. 5c; Table S2), in accordance with the upregulation of the succinate dehydrogenase [ubiquinone] flavoprotein subunit and mitochondria and as represented by MF categories such as mitochondrial electron transport, succinate to ubiquinone (Fig. 5c) and citrate cycle (Fig. 6b). These processes might occur in CCs, such as the mitochondrial matrix, mitochondrial respiratory chain complex II, and succinate dehydrogenase complex (ubiquinone) (Fig. 5c). In addition, the GMP biosynthetic process, GMP metabolic process, hydrolase activity (hydrolyzing O-glycosyl compounds), glycosyl compound metabolic process and glycosyl compound biosynthetic process were significantly represented (Table S2). These results indicate that half-degraining may affect energy generation in the remaining grains. In the $\mathrm{BP}$ analysis, we indeed observed that categories related energy generation were upregulated, including generation of precursor metabolites and energy, and electron transport coupled ATP synthesis coupled electron transport (Table S2).

In our study, the relative ROS content increased in the LDef group (Fig. 3), which might inhibit photosynthesis [56], as discussed above. However, glutathione stransferase, superoxide dismutase (fragment), and oxidoreductase activity, which act on superoxide radicals as acceptors; SOD activity (Fig. 3); oxidation-reduction process; oxidoreduction coenzyme metabolic process; and tocopherol cyclase and glutathione S-transferase (Table S1) and thus tocopherol cyclase activity were upregulated (Table S2), indicating that in the LDef group, some strategies may have developed to help plants scavenge ROS and eliminate oxidative damage [73, 74]. However, the overall capability of ROS metabolic processes, removal of superoxide radicals, cellular response to superoxide, cellular response to oxygen radicals, regulation of $\mathrm{H}_{2} \mathrm{O}_{2}$ metabolic process and cellular response to ROS were downregulated (Table S2).

Interestingly, the top 20 significantly represented BPs were upregulated in the LDef group (Table S2). GO terms related to photosynthesis were significantly enriched but showed different changing trends. For instance, plastid organization and cofactor metabolic processes were upregulated. DEPs related to photosynthesis-antenna proteins and carbon metabolism were also upregulated (Fig. S1B). However, chlorophyll biosynthetic, chlorophyll metabolic and pigment biosynthetic processes were downregulated (Table S2). These results indicate that leaf photosynthesis may be affected (Fig. 5b). According to MF analysis, iron-sulfur cluster binding, $2 \mathrm{Fe}-2 \mathrm{~S}$ iron-sulfur cluster binding and $3 \mathrm{Fe}-4 \mathrm{~S}$ iron-sulfur cluster binding, which play important roles in the photosynthetic rate by regulating electron transfer and the chlorophyll content in rice [75], were significantly affected. Accordingly, many MF categories, including the activities of electron carrier, protontransporting ATPase, hydrogen-exporting ATPase, hydrogen ion transmembrane transporter and plastoquinol-plastocyanin reductase, were changed (Fig. 5 b; Table S2), indicating that the energy supply might be very important in the LDef group. Indeed, the GO categories that were enriched and primarily related to energy metabolism were upregulated, including the glyceraldehyde-3-phosphate metabolic process, glucose 6-phosphate metabolic process, carbohydrate derivative metabolic process and generation of precursor metabolites and energy via the pentose-phosphate pathway and pentose-phosphate shunt (Table S2).

In the LDef group, peptidyl-prolyl cis-trans isomerase and peptidylprolyl isomerase were enriched, which could affect protein folding and interact with the chlorophyll $\mathrm{a}-\mathrm{b}$ binding protein and cytochrome $b-c 1$ complex 
subunit Rieske as shown in Fig. S1B. Regarding lipid metabolism, organophosphate metabolic, cellular lipid metabolic, lipid biosynthetic and phospholipid biosynthetic processes were also upregulated in the LDef group. In addition, protein glutathionylation, a mechanism of redox regulation and signaling [66], and oxidation-reduction processes were downregulated, indicating a possible decrease in the ability to scavenge ROS.

In BP category analysis of the GDef group, organonitrogen compound metabolic and cellular protein metabolic processes were enhanced. However, protein folding was downregulated (Table S2); in addition, translation, peptide biosynthetic, peptide metabolic and L-proline biosynthetic processes were downregulated. As a consequence, a large number of low molecular weight glutenins (subunits) were decreased (Table S2). These processes may occur in the ER lumen, prefolding complex and ribosome, regulating the structural constituents of ribosomes (Table S2), especially in the ER, because protein processing in the ER was significantly affected (Fig. 6b).

In the GDef group, the glucose 6-phosphate metabolic process and the generation of precursor metabolites and energy were downregulated (Table S2). Pyruvate kinase was decreased, and pyruvate kinase activity was decreased (Table S1, S2). At the same time, the chlorophyll a-b binding protein (chloroplastic) was also downregulated. Furthermore, photosynthesis, light harvesting and the light reaction were also decreased. These results indicate that in the grains of defoliated plants, the photosynthetic efficiency and energy generation may be affected.

Based on these results and those discussed above, we further surmise that defoliation hinders endosperm development, seed development and maturation, as shown in Table S2.

A large amount of macromolecules in normal senescent leaves are degraded into small molecules by degradation enzymes [76], which leads to a massive remobilization of phloem-mobile nutrients from senescing plant parts to developing sinks [22, 77].

As suggested by the proteomic analysis results, the source-sink modifications mainly affected nitrogen and carbon metabolism and energy production. During leaf senescence in plants, genes encoding proteases are overexpressed [78-81]. A large number of senescenceassociated proteases are upregulated, and the resulting catabolic products are mobilized from leaves to developing grains [76, 82-84]. The activity of amylases plays a vital role in starch degradation and the remobilization of nonstructural carbohydrates from vegetative organs to developing sinks and is thus essential for grain filling $[85,86]$. In the present study, defoliation increased the activities of amylase (Fig. 7) and acid and alkaline proteinases (Fig. 7). Half-degraining decreased proteinase activity at 16 and 24 DAM and amylase activity at 24 DAM. These results indicate that the earlier senescence of defoliated plants might be partially due to the increases of the activities of these hydrolytic enzymes and the earlier nutrient remobilization from a smaller leaf area in defoliated plants, while the delayed senescence in half-degrained plants might be partially caused by decreased protein and starch degradation.

Vegetative organ CTKs play an important role in regulating senescence, which is associated with a delay in proteolytic activity and thus nitrogen remobilization to developing grains [87-89]. Therefore, we speculate that the decrease in the CTK concentration may be associated with the increases in proteolytic activity in the LDef group.

\section{Conclusions}

In this study, the reduced sink/source ratio due to halfdegraining delayed wheat leaf senescence, while the higher sink/source ratio due to defoliation caused a higher amount of ROS production and facilitated the degradation of chlorophyll-protein complexes and carbohydrates and thus plant senescence. CTKs, IAA and JA and the interactions among these hormones played major roles in regulating the source capability and sink strength, thereby impacting the process of leaf senescence. Sink and source manipulations induced many differentially expressed proteins, which were mainly involved in ROS scavenging, leaf photosynthesis, carbon and nitrogen metabolism, generation of precursor metabolites and energy and grain development. Degradation of carbohydrates and proteins by hydrolytic enzyme activities was promoted in the flag leaves of defoliated plants but retarded in those of half-degrained plants, which in turn, impacted carbon and nitrogen metabolism in grains. Half-spike removal enhanced but defoliation depressed single grain growth, indicating that the yield potential of wheat is limited by both the sink capacity and source availability. Our results indicate that future yield improvements may be able to be achieved by strengthening both the source and sink capacities during breeding to increase the yield potential in wheat.

\section{Methods}

\section{Site, experiment and design}

The experiments were conducted in the 2017-2018 cropping season in a field at an experimental station $\left(36^{\circ} 42^{\prime} \mathrm{N}, 117^{\circ} 4^{\prime} \mathrm{E}\right.$; altitude $\left.48 \mathrm{~m}\right)$ of the Shandong Academy of Agricultural Sciences, China. The soil was a fine loam. Wheat cultivar Jimai 23, which was developed by the Crop Research Institute, Shandong Academy of Agricultural Sciences, was used in this experiment. Jimai 23 is a representative of varieties that are popularly 
grown in northern China due to their high grain yield. Seeds were sown on Oct. 10, 2017, at a rate of 225 seeds $\mathrm{m}^{-2}$ in three blots (each of $30 \mathrm{~m}^{2}$ ). Plots were fertilized before planting with $10 \mathrm{~g} \mathrm{~m}^{-2} \mathrm{P}_{2} \mathrm{O}_{5}, 10 \mathrm{~g} \mathrm{~K}_{2} \mathrm{O} \mathrm{m}{ }^{-2}$ and $7.5 \mathrm{~g} \mathrm{~N} \mathrm{~m}^{-2}$. At the shooting stage (Zadoks stage 31), 15 $\mathrm{g} \mathrm{N} \mathrm{m}^{-2}$ was top-dressed with urea. Matured grains were harvested on Jun. 6, 2018.

\section{Source and sink manipulations}

Sink-source manipulations were conducted as follows: (1) all spikelets were manually removed from one side of the spikes to double the assimilate availability for the remaining grains; (2) all leaves of culms except flag leaves were removed to reduce the source assimilate availability. Each manipulation was performed in three $2-\mathrm{m}$ sections of the rows at 2 days after anthesis in each plot. Three 2-m sections were selected and were left intact as a control.

\section{Measurement of vegetation index}

NDVI and PRI were measured with a PlantPen instrument (Photon Systems Instruments, Brno, Czech Republic) from 30 flag leaves per plot. The SPAD index was determined from at least 30 flag leaves per plot using a chlorophyll meter (SPAD-502 plus, Konica Minolta, INC., Japan) at 8, 16 and 24 DAM. Data from each plot were averaged to obtain themean.

\section{Chlorophyll fluorescence assay and imaging}

Chlorophyll fluorescence analysis was performed at different stages to determine $F v / F m$ and $\Phi_{\text {PSII }}$ in flag leaves using a kinetic imaging fluorometer (FluorCam, Photon System Instruments Ltd., Brno, Czech Republic) as described by Kong et al. [90].

\section{Transmission Electron microscopy (TEM)}

TEM observations were processed as reported previously by Kong et al. [90] using a transmission electron microscope (JEM-1200EX; JEOL Ltd., Tokyo, Japan) at $80 \mathrm{kV}$.

\section{Hormone analysis}

Flag leaves or spikes in triplicate from each treatment were collected from three biological replicates at 8,16 and 24 DAM; immediately frozen in liquid nitrogen; and then stored at $-80^{\circ} \mathrm{C}$. Then, the leaves and grains were used for each hormone analysis.

The extraction and purification of zeatin, zeatin riboside, kinetin, and IAA were performed according to Liu et al. [34]. Briefly, samples (approximately $0.10 \mathrm{~g}$ flag leaves or grains) were ground in a pre-cooled mortar containing $5 \mathrm{ml}$ of an $80 \%(\mathrm{v} / \mathrm{v})$ methanol extraction solution and $1 \mathrm{mM}$ butylated hydroxytoluene was added as an antioxidant. The resulting extracts were incubated overnight at $4{ }^{\circ} \mathrm{C}$ and then centrifuged at $12000 \times g$ for
15 min at $4{ }^{\circ} \mathrm{C}$. The supernatants were dried with $\mathrm{N}_{2}$ at $40{ }^{\circ} \mathrm{C}$, dissolved in $200 \mu \mathrm{l}$ methanol and filtered through a membrane $(0.45 \mu \mathrm{m})$. High-performance liquid chromatography (HPLC; Rigol L3000, Beijing, China) with a Kromasil C18 reversed-phase column was used to measure the hormone concentration. The mobile phase was prepared by mixing methanol and ultrapure water at a ratio of 2:3 (v/v). The injection volume was $10 \mu \mathrm{l}$, the flow rate was $0.8 \mathrm{ml} / \mathrm{min}$, the column temperature was $35^{\circ} \mathrm{C}$, the elution time was $60 \mathrm{~min}$, and the detection wavelength was $254 \mathrm{~nm}$. Three independent biological replicates of each sample were performed.

For JA analysis, the sample (approximately $0.10 \mathrm{~g}$ ) was ground to a fine powder in liquid nitrogen and extracted with $1.0 \mathrm{ml}$ of $90 \%(\mathrm{v} / \mathrm{v})$ methanol overnight at $4{ }^{\circ} \mathrm{C}$. The crude extract was centrifugated at $12000 \times g$ for $10 \mathrm{~min}$ and the supernatant was collected. The resulting precipitate was then re-extracted with $0.5 \mathrm{ml}$ of $90 \%$ methanol for $2 \mathrm{~h}$ and recentrifuged. After two times of extractions, the supernatants were combined and air-dried by incubation at $40^{\circ} \mathrm{C}$. The dried samples were dissolved in 1 $\mathrm{ml}$ of ethylacetate/cyclopentane (1:1, v:v) and $20 \mu \mathrm{l}$ of 1 $\mathrm{mg} / \mathrm{ml}$ trichloroacetic acid, followed by vortexing for 30 min and centrifuged at $8000 \times g$ for $10 \mathrm{~min}$. The top organic phase was dried, dissolved in mobile phase and injected into a reverse phase C18 HPLC column equipped with a fluorescence detector for analysis of JA. The mobile phase was prepared by mixing methanol and $0.1 \%$ formic acid $(65 \%: 35 \%, \mathrm{v} / \mathrm{v})$. The injection volume was $10 \mu \mathrm{l}$, flow rate was $0.8 \mathrm{ml} / \mathrm{min}$, column temperature was $35^{\circ} \mathrm{C}$, and elution time was $30 \mathrm{~min} ; 230 \mathrm{~nm}$ was monitored. At least three independent biological replicates of each sample were performed.

\section{Protein preparation}

Leaves (approximately $0.1 \mathrm{~g}$ FW for each biological replicate) were ground into a fine powder in liquid nitrogen and thoroughly transferred to an Eppendorf tube. To the tube, $1 \mathrm{ml}$ of precooled phenol extraction buffer (100 $\mathrm{mM}$ Tris- $\mathrm{HCl}, 50 \mathrm{mM}$ EDTA, $100 \mathrm{mM} \mathrm{KCl,} \mathrm{2 \%} \mathrm{(w/v)}$ DTT, 30\% sucrose and 2\% SDS; pH 8.0) was added, and the mixture was incubated at room temperature for 10 min. Then, $1 \mathrm{ml}$ phenol saturated with Tris- $\mathrm{HCl}(\mathrm{pH} 8.0)$ was added. The mixture was shaken for $40 \mathrm{~min}$ at $4{ }^{\circ} \mathrm{C}$. After centrifugation at $12000 \times g$ for $15 \mathrm{~min}$ at $4{ }^{\circ} \mathrm{C}$, the upper phenolic phase was collected, debris was removed, and protein was precipitated with precooled $100 \mathrm{mM}$ ammonium acetate-methanol solution for $12 \mathrm{~h}$ at $20^{\circ} \mathrm{C}$. After centrifugation, the pellet was washed three times with cold acetone and air-dried for $5 \mathrm{~min}$. Protein was resuspended in $600 \mu \mathrm{l}$ of lysis buffer (4\% SDS, 100 $\mathrm{mM}$ Tris- $\mathrm{HCl}, 1 \mathrm{mM}$ DTT, $\mathrm{pH} 7.6$ ), incubated for 60 min at room temperature and centrifuged at $12000 \times g$ for $10 \mathrm{~min}$ at room temperature. The sample was 
collected and stored at $-80^{\circ} \mathrm{C}$ for iTRAQ analysis. The protein concentration was determined according to the Bradford assay (Bradford, 1976).

\section{Trypsin digestion and iTRAQ labeling}

Approximately $100 \mu \mathrm{g}$ of protein from each biological replicate was used for digestion. First, the protein sample was reduced by the addition of $120 \mu$ l buffer $(10 \mathrm{mM}$ DTT, $8 \mathrm{M}$ urea, $100 \mathrm{mM}$ tetraethylammonium bromide (TEAB), pH 8.0) at $60^{\circ} \mathrm{C}$ for $1 \mathrm{~h}$ and then alkylated using $50 \mathrm{mM}$ iodoacetamide for $40 \mathrm{~min}$ at room temperature in the dark. Subsequently, the proteins (precisely $0.1 \mathrm{mg}$ ) were diluted with $100 \mu \mathrm{l} 100 \mathrm{mM}$ TEAB. Then, $2 \mu \mathrm{l}$ sequencing-grade trypsin $(1 \mu \mathrm{g} / \mu \mathrm{l}$; Promega $)$ was added for digestion at $37^{\circ} \mathrm{C}$ for $12 \mathrm{~h}$. After centrifugation at $12000 \times g$ for $20 \mathrm{~min}$, the supernatant was collected and lyophilized. The lyophilized sample was thawed and reconstituted in $100 \mu \mathrm{l} 100 \mathrm{mM}$ TEAB. The $100 \mu \mathrm{l}$ iTRAQ reagent was transferred to the sample tube and labeled by incubation for $2 \mathrm{~h}$ at room temperature. After the addition of $200 \mu \mathrm{l}$ water to quench the labeling reaction, the solution was lyophilized.

\section{Mass spectrometry (MS) analysis}

The labeled peptides were subjected to a nanospray Flex source and analyzed by a Q-Exactive mass spectrometer (Thermo, USA). The following analyses were performed according to the procedures as described by $\mathrm{Xu}$ et al. [91] and Xiong et al. [92].

\section{Protein identification and quantification}

The resulting MS/MS spectral data files were analyzed using Proteome Discoverer ${ }^{\mathrm{TM}} 1.3$ (Thermo, USA) software using the SEQUEST $^{\circledR}$ search engine and were searched against the UniProt Triticum aestivu. FASTA database for wheat at a $1 \%$ FDR. The mass errors of precursor ions and fragment ions were set to $10 \mathrm{ppm}$ and $0.02 \mathrm{Da}$, respectively.

The screening criteria for reliable proteins were as follows: unique peptide $\geq 1$, removal of invalid values and antilibrary data, and screening of differentially expressed proteins based on reliable proteins. To screen differential proteins, Student's $t$-test $p<0.05$ and fold changes $>1.3$ or $<0.77$ across the flag leaf samples or more than 1.5fold or less than 0.67 -fold were selected across the grain samples from a control, and two treatments were applied based on two experiments.

\section{Bioinformatics analysis}

A database (http://www.omicsbean.com:88/) and the OmicsBean software (http://www.ebi.ac.uk/interpro/) were used for gene ontology (GO) annotation. In the OmicsBean software, each protein was assigned to biological processes, cellular components and molecular functions. After annotation, proteins were mapped to pathways in the Kyoto Encyclopedia of Genes and Genomes (KEGG) database (http://www.kegg.jp/). PPI analysis was also performed using Cytoscape software.

\section{Enzyme assays}

For total amylase activity, flag leaves (approximately 0.1 g FW) were collected from three replicates and homogenized in a prechilled mortar and pestle with $1 \mathrm{ml}$ cooled distilled water. After adding another $9 \mathrm{ml}$ of distilled water, the mixture was placed at room temperature for $20 \mathrm{~min}$ to extract total amylase. Then, the homogenate was centrifuged at $12000 \times g$ for $15 \mathrm{~min}$ at $4{ }^{\circ} \mathrm{C}$. The supernatant was separated and used as the enzyme extract. To $1 \mathrm{ml}$ enzyme extract, $1 \mathrm{ml}$ soluble starch $(1 \%$, $\mathrm{w} / \mathrm{v}$ ) or $1 \mathrm{ml}$ distilled water (control) was added and incubated at $40{ }^{\circ} \mathrm{C}$ for $5 \mathrm{~min}$. Subsequently, $2 \mathrm{ml}$ of 3,5dinitrosalicylic acid reagent (1\% (w/v) 3,5-dinitrosalicylic acid and $100 \mathrm{mM}$ phosphate buffer ( $\mathrm{pH} 7.0)$ ) was added to the mixture before heating in a boiling water bath. Absorbance was measured at $540 \mathrm{~nm}$ using a spectrophotometer. The enzyme activity is expressed as the amount of enzyme catalyzing the production of $1 \mathrm{mg}$ reducing sugar per min per mg protein.

Protease (EC 3.4.21.40) activity was spectrophotometrically determined using casein as the substrate. Flag leaves (approximately $0.1 \mathrm{~g} \mathrm{FW)} \mathrm{were} \mathrm{ground} \mathrm{in} \mathrm{a} \mathrm{mor-}$ tar. The homogenates were centrifuged at $12000 \times g$ for $15 \mathrm{~min}$ at $4{ }^{\circ} \mathrm{C}$, and the supernatant was transferred to a test tube for the measurement of protease activity. The reaction mixture containing $1 \mathrm{ml}$ enzyme extract and 1 $\mathrm{ml}$ casein (2\%) was heated at $40{ }^{\circ} \mathrm{C}$ for $10 \mathrm{~min}$. A trichloroacetic acid solution ( $2 \mathrm{ml} 5 \%)$ was added to the reaction for $20 \mathrm{~min}$ at $40^{\circ} \mathrm{C}$. After centrifugation (12, $000 \times g, 10 \mathrm{~min})$, a reaction mixture containing $1 \mathrm{ml}$ supernatant, $5 \mathrm{ml} \mathrm{Na} \mathrm{CO}_{3}(0.5 \mathrm{M})$, and $1 \mathrm{ml}$ Folin reagent was prepared, and its absorbance was then colorimetrically measured at $680 \mathrm{~nm}$. The $\mathrm{pH}$ of the incubation media for acid proteinase, neutral proteinase, and alkaline proteinase buffer solutions were 3.6, 7.5 and 11 , respectively. The activities of proteases were estimated by measuring tyrosine and other aromatic amino acids released from hydrolyzed proteins according to a standard curve. Activity is expressed as nmol tyrosine released per min per mg protein.

\section{Grain mass}

Eighty culms were harvested from each plot at maturity and threshed by hand. The grains were oven-dried at $60{ }^{\circ} \mathrm{C}$ to a constant weight. Grains were then weighed, and the grain number was counted to obtain single grain mass. The grain mass and grain number were determined based on half-spikes. 


\section{Statistical analysis}

For the physiological indices obtained, statistical analyses were performed using the software of the data processing system (DPS) (v.14.10, Refine Information Tech. Co., Ltd., Hangzhou, Zhejiang, China). Duncan's multiple range test was used to evaluate the statistical significance of the results.

\section{Supplementary information}

Supplementary information accompanies this paper at https://doi.org/10. 1186/s12870-020-02447-8.

Additional file $\mathbf{1}$ Table $\mathbf{S 1}$. Detailed information of the DEPs identified by ITRAQ in the LDG and LDef groups in comparison with the LC group and in the GDG and GDef groups in comparison with the GC group. GC, grains in control plants; GDef, grains in defoliated plants; GDG, grains in de-grained plants; LC, leaves in control plants; LDef, leaves in defoliated plants; LDG, leaves in the de-grained plants

Additional file $\mathbf{2}$ Table S2. Two manipulation-related DEPs identified in GO categories and were grouped into three levels: biological process (BP), cellular component (CC) and molecular function (MF)

Additional file 3 Fig. S1. Interaction networks of the differentially expressed proteins in comparison of LDG/LC (A), LDef/LC (B), GDG/GC (C) and GDef/GC (D). GC, grains in control plants; GDef, grains in defoliated plants; GDG, grains in de-grained plants; LC, leaves in control plants; LDef, leaves in defoliated plants; LDG, leaves in the de-grained plants. Circle nodes denote differentially expressed proteins (genes), and colored rectangles indicate KEGG pathways. PPI analysis was performed using Cytoscape software, in which the threshold value (confidence cutoff) was set at 400, when the confidence score of the potential PPI was high, as indicated by solid lines or dashed lines. A solid line between two proteins indicates a known interaction annotated in the database; a dashed line between proteins indicates a potential interaction

\section{Abbreviations}

ACP: Acid proteinase; AGC: Automatic gain control; AKP: Alkaline proteinase BADH: Betaine aldehyde dehydrogenase; BP: Biological process;

CAT: Catalase; CC: Cell component; CTKs: Cytokinins; DAM: Days after manipulation; DEP: Differentially expressed protein; DHAR: Dehydroascorbate reductase; DPS: Data processing system; DTT: Dithiothreitol; EDTA: Ethylene diamine tetraacetic acid; Fd-GOGAT: Ferredoxin-dependent glutamate synthase; FDR: False-discovery rate; ER: Endoplasmic reticulum; FV/ Fm: Maximum PSII quantum yield; GC: Grains in control plants; GDef: Grains in defoliated plants; GDG: Grains in de-grained plants; $\mathrm{H}_{2} \mathrm{O}_{2}$ : Hydrogen peroxide; HPLC: High-performance liquid chromatography; IAA: Indoleacetic 3-acid; iTRAQ: Isobaric tag for relative and absolute quantitation; JA: Jasmonic acid; KEGG: Kyoto encyclopedia of genes and genomes; LC: Leaves in control plants; LDef: Leaves in defoliated plants; LDG: Leaves in de-grained plants; MF: Molecular function; MS: Mass spectrometry; NDVI: Normalized difference vegetation index; NP: Neutral proteinase $\mathrm{O}_{2}^{-{ }^{-}}$: Superoxide; PDI: Protein disulfide isomerase; POD: Peroxidase; PPI: Protein-protein interaction; PRI: Photochemical reflectance index; SDS: Sodium dodecyl sulfate; SOD: Superoxide dismutase; SPAD: Soil and plant analyzer development; TEAB: Tetraethylammonium bromide; $\Phi_{\text {PSII: }}$ Effective PSII quantum yield

\section{Acknowledgments}

The authors would thank Shanghai Luming Biotechnology Co., Ltd. for their technological assistance with proteomic analysis.

\section{Authors' contributions}

LK conceived and designed the experiments; $X L$ and $Y Z$ performed the experiments; YXZ and SF analyzed the data; $X L$ and LK wrote the manuscript. All the authors read and approved the final manuscript. LK agrees to serve as the author responsible for contact and ensures communication. All the authors read and approved the manuscript.

\section{Funding}

This work was supported by the National Key R \& D Program of China (2016YFD0300403, 2017YFD03002), the National Natural Science Foundation of China (31801282), the Shandong Modern Agricultural Technology and Industry System (SDAIT-01-06) and the National Earmarked Fund for Modern Agro-industry Technology Research System (CARS-3-1-21). Funds were used for the experimental implementation, sampling, proteomic analysis and interpretation of data.

\section{Availability of data and materials}

The datasets generated and analyzed during the present study and the plant materials used in the present study are available from the corresponding author upon reasonable request.

Ethics approval and consent to participate

Not applicable.

Consent for publication

Not applicable.

\section{Competing interests}

The authors declare that they have no conflicts of interest.

Received: 12 August 2019 Accepted: 14 May 2020

Published online: 05 June 2020

\section{References}

1. Foulkes MJ, Slafer GA, Davies WJ, Berry PM, Sylvester-Bradley R, Martre P, Calderini DF, Griffiths S, Reynolds MP. Raising yield potential of wheat. III. Optimizing partitioning to grain while maintaining lodging resistance. J Exp Bot. 2011;62:469-86.

2. Calderini DF, Reynolds MP. Changes in grain weight as a consequence of de-graining treatments at pre- and post-anthesis in synthetic hexaploid lines of wheat (Triticum durum $\times$ T. tauschii). Aus J Plant Physiol. 2000;27: 183-91.

3. Calderini DF, Reynolds MP, Slafer GA. Source-sink effects on grain weight of bread wheat, durum wheat, triticale at different locations. Aust J Agric Res. 2006;57:227-33.

4. Kruk B, Calderini DF, Slafer GA. Source-sink ratios in modern and old wheat cultivars. J Agr Sci. 1997;128:273-81.

5. Beed FD, Paveley ND, Sylvester-Bradley R. Predictability of wheat growth and yield in light-limited conditions. J Agr Sci. 2007;145:63-79.

6. Borrás L, Slafer GA, Otegui ME. Seed dry weight response to source-sink manipulations in wheat, maize and soybean: a quantitative reappraisal. Field Crops Res. 2004;86:131-46.

7. Slafer GA, Savin R. Source-sink relationships and grain mass at different positions within the spike in wheat. Field Crops Res. 1994:37:39-49.

8. Borrill P, Fahy B, Smith AM, Uauy C. Wheat grain filling is limited by grain filling capacity rather than the duration of flag leaf photosynthesis: a case study using NAM RNAi plants. PLoS One. 2015;10(8):e0134947. https://doi. org/10.1371/journal.pone.0134947.

9. Chang TG, Zhu XG. Source-sink interaction: a century old concept under the light of modern molecular systems biology. J Exp Bot. 2017;68:4417-31.

10. Jan S, Abbas N, Ashraf M, Ahmad P. Roles of potential plant hormones and transcription factors in controlling leaf senescence and drought tolerance. Protoplasma. 2019:256:313-29.

11. Yang JC, Peng SB, Visperas RM, Sanico AL, Zhu QS, Gu SL. Grain filling pattern and cytokinin content in the grains and roots of rice plants. Plant Growth Regul. 2000;30:261-70.

12. Paul MJ, Foyer $\mathrm{CH}$. Sink regulation of photosynthesis. J Exp Bot. 2001;52: 1383-400.

13. Thomas H, Ougham H. The stay-green trait. J Exp Bot. 2014:65:3889-900

14. Karp NA, Huber W, Sadowski PG, Charles PD, Hseter SV, Lilley KS. Addressing accuracy and precision issues in ITRAQ quantitation. Mol Cell Proteomics. 2010:9:1885-97.

15. Yang M, Dong J, Zhao W, Gao X. Characterization of proteins involved in early stage of wheat grain development by iTRAQ. J Proteome. 2016;136: 157-66.

16. Ford KL, Cassin A, Bacic A. Quantitative proteomic analysis of wheat cultivars with differing drought stress tolerance. Front Plant Sci. 2011;2:44. 
17. Ma YZ, MacKown CT, van Sanford DA. Differential effects of partial spikelet removal and defoliation on kernel growth and assimilate partitioning among wheat cultivars. Field Crops Res. 1996;47:201-9.

18. Serrago RA, Alzueta I, Savin R, Slafer GA. Understanding grain yield responses to source-sink ratios during grain filling in wheat and bar ley under contrasting environments. Field Crops Res. 2013;150:42-51.

19. Cartelle J, Pedró A, Savin R, Slafer GA. Grain weight responses to postanthesis spikelet-trimming in an old and a modern wheat under Mediterranean conditions. Europ J Agron. 2006;25:365-71.

20. Jessica B, Pierre M, Bruno A. Dynamics of light and nitrogen distribution during grain filling within wheat canopy. Plant Physiol. 2008;148:1707-20.

21. Yang J, Zhang J. Grain-filling problem in 'super' rice. J Exp Bot. 2010;61:1-5.

22. Camargo AV, Mott R, Gardner KA, Mackay IJ, Corke F, Doonan JH, Kim JT, Bentley AR. Determining phenological patterns associated with the onset of senescence in a wheat MAGIC mapping population. Front Plant Sci. 2016;7: 1540.

23. Fu J, Huang ZH, Wang ZQ, Yang JC, Zhang JH. Pre-anthesisnon-structural carbohydrate reserve in the stem enhances the sink strength of inferior spikelets during grain filling of rice. Field Crops Res. 2011;123:170-82.

24. Chen M, Maodzeka A, Zhou L, Ali E, Wang Z, Jiang L. Removal of DELLA repression promotes leaf senescence in Arabidopsis. Plant Sci. 2014;219:26-34

25. Kang G, Peng X, Wang L, Yang Y, Shao R, Xie Y, Ma D, Wang C, Guo T, Zhu $Y$. Ultrastructural observation of mesophyll cells and temporal expression profiles of the genes involved in transitory starch metabolism in flag leaves of wheat after anthesis. Physiol Plantarum. 2015;153:12-29.

26. Kong LA, Xie Y, Hu L, Si J, Wang Z. Excessive nitrogen application dampens antioxidant capacity and grain filling in wheat as revealed by metabolic and physiological analyses. Sci Rep. 2017;7:43363.

27. Lyu Jl, Baek SH, Jung S, Chu H, Nam HG, Kim J, Lim PO. High-throughput and computational study of leaf senescence through a phenomic approach. Front Plant Sci. 2017:8:250

28. Vicente R, Vergara-Díaz O, Medina S, Chairi F, Kefauver SC, Bort J, Serret MD, Aparicio N, Araus JL. Durum wheat ears perform better than the flag leaves under water stress: gene expression and physiological evidence. Environ Exp Bot. 2018;153:271-85.

29. Chen Z, Gallie DR. Dehydroascorbate reductase affects leaf growth, development, and function. Plant Physiol. 2006;142:775-87.

30. Semwal VK, Khanna-Chopra R. Reproductive sink enhanced drought induced senescence in wheat fertile line is associated with loss of antioxidant competence compared to its CMS line. Physiol Mol Biol Plants. 2018;24:591-604

31. Hui Z, Tian FX, Wang G, Wang GP, Wang W. The antioxidative defense system is involved in the delayed senescence in a wheat mutant tasg1. Plant Cell Rep. 2012;31:1073-84.

32. Yang JC, Zhang JH, Wang ZQ, Zhu QS, Wang W. Hormonal changes in the grains of rice subjected to water stress during grain filling. Plant Physiol. 2001;127(1):315-23.

33. Yang JC, Zhang JH. Grain filling of cereals under soil drying. New Phytol. 2006;169:223-36.

34. Liu Y, Liang $H$, Lv X, Liu D, Wen $X$, Liao $Y$. Effect of polyamines on the grain filling of wheat under drought stress. Plant Physiol Bioch. 2016;100:113-29.

35. Yang JC, Zhang JH, Huang ZL, Wang ZQ, Zhu QS, Liu L. Correlation of cytokinin levels in the endosperms and roots with cell number and cell division activity during endosperm development in rice. Ann Bot (London). 2002:90:369-77.

36. Afzal I, Basra SMA, lqbal A. The effects of seed soaking with plant growth regulators on seedling vigor of wheat under salinity stress. J Stress Physiol Biochem. 2005;1:6-14.

37. Biswas AK, Mondal SK. Regulation by kinetin and abscisic acid of correlative senescence in relation to grain maturation, source-sink relationship and yield of rice (Oryza sativa L.). Plant Growth Regul. 1986;4(3):239-45.

38. Reguera M, Peleg Z, Abdel-Tawab YM, Tumimbang EB, Delatorre CA Blumwald E. Stress-induced cytokinin synthesis increases drought tolerance through the coordinated regulation of carbon and nitrogen assimilation in rice. Plant Physiol. 2013;163:1609-22.

39. Xu GW, Zhang JH, Lam HM, Wang ZQ, Yang JC. Hormonal changes are related to the poor grain filling in the inferior spikelets of rice cultivated under non-flooded and mulched condition. Field Crop Res. 2007;101:53-61.

40. He P, Osaki M, Takebe M, Shinano T, Wasaki J. Endogenous hormones and expression of senescence-related genes in different senescent types of maize. J Exp Bot. 2005;56:1117-28.
41. Yang JC, Cao YY, Zhang H, Liu L, Zhang JH. Involvement of polyamines in the post-anthesis development of inferior and superior spikelets in rice. Planta. 2008:228:137-49.

42. Zhang $\mathrm{H}$, Tan $\mathrm{GL}$, Yang LN, Yang JC, Zhang JH, Zhao BH. Hormones in the grains and roots in relation to post-anthesis development of inferior and superior spikelets in japonica/indica hybrid rice. Plant Physiol Biochem. 2009;47:195-204.

43. Dietrich JT, Kaminek M, Blevins DG, Reinbott TM, Morris RO. Changes in cytokinins and cytokinin oxidase activity in developing maize kernels and the effects of exogenous cytokinin on kernel development. Plant Physiol Biochem. 1995;33:327-36.

44. Yang D, Li Y, Shi Y, Cui Z, Luo Y, Zheng M, Chen J, Li Y, Yin Y, Wang Z. Exogenous cytokinins increase grain yield of winter wheat cultivars by improving stay-green characteristics under heat stress. PLoS One. 2016;11(5): e0155437.

45. Zhang W, Cao Z, Zhou Q, Chen J, Xu G, Gu J, Liu L, Wang Z, Yang J, Zhang $H$. Grain filling characteristics and their relations with endogenous hormones in large- and small-grain mutants of rice. PLoS One. 2016;11(10): e0165321.

46. Rijavec T, Kovać M, Kladnik A, Chourey PS, Dermastia M. Comparative study on the role of cytokinins in caryopsis development in the maize miniature1 seed mutant and its wild type. J Integr Plant Biol. 2009;51:840-9.

47. Yu SM, Lo SF, Ho THD. Source-sink communication: regulated by hormone, nutrient, and stress cross-signaling. Trends Plant Sci. 2015;20:844-57.

48. Lu HS, Setter TL. Endosperm development of maize defective kernel (dek). Mutants. Auxin and cytokinin levels. Ann Bot (London). 1993;72:1-6.

49. Seth AK, Waering PE. Hormone-directed transport of metabolites and its possible role in plant senescence. J Exp Bot. 1967;18:65-77.

50. Singh G, Gerung SB. Hormonal role in the problem of sterility in Oryza sativa. Plant Physiol Biochem. 1982;9:22-3.

51. Du Y, Fan L, Tian C, Wu T. Auxin positively regulates nitrogen remobilization in cucumber leaves. Hortic Environ Biotechnol. 2018;59:189.

52. Kong L, Guo H, Sun M. Signal transduction during wheat grain development. Planta. 2015;241:789-801.

53. Wang Z, Wang Y, Hong X, Hu D, Liu C, Yang J, Li Y, Huang Y, Feng Y, Gong $\mathrm{H}$, Li Y, Fang G, Tang H, Li Y. Functional inactivation of UDP-Nacetylglucosamine pyrophosphorylase 1 (UAP1) induces early leaf senescence and defence responses in rice. J Exp Bot. 2015;66:973-87.

54. Tamaki H, Reguera M, Abdel-Tawab YM, Takebayashi Y, Kasahara H, Blumwald E. Targeting hormone-related pathways to improve grain yield in rice: a chemical approach. PLoS One. 2015;10(6):e0131213.

55. Exposito-Rodriguez M, Laissue PP, Yvon-Durocher G, Smirnoff N, Mullineaux PM. Photosynthesis-dependent $\mathrm{H}_{2} \mathrm{O}_{2}$ transfer from chloroplasts to nucle provides a high-light signalling mechanism. Nat Commun. 2017;8:4.

56. Wang P, Liu J, Liu B, Da Q, Feng D, Su J, Zhang Y, Wang J, Wang HB. Ferredoxin:thioredoxin reductase is required for proper chloroplast development and is involved in the regulation of plastid gene expression in Arabidopsis thaliana. Mol Plant. 2014;7:1586-90.

57. Geigenberger $P$, Thormählen I, Daloso DM, Fernie AR. The unprecedented versatility of the plant thioredoxin system. Trends Plant Sci. 2017;22:249-62.

58. Li H, Wang G, Liu S, An Q, Zheng Q, Li B, Li Z. Comparative changes in the antioxidant system in the flag leaf of early and normally senescing nearisogenic lines of wheat (Triticum aestivum L.). Plant Cell Rep. 2014;33:1109-20.

59. Parihar $P$, Singh $S$, Singh $R$, Singh VP, Prasad SM. Effect of salinity stress on plants and its tolerance strategies: a review. Environ Sci Pollut R. 2015;22: 4056-75.

60. Hicks LM, Cahoon RE, Bonner ER, Rivard RS, Sheffield J, Jez JM. Thiol-based regulation of redox-active glutamate-cysteine ligase from Arabidopsis thaliana. Plant Cell. 2007;19:2653-61.

61. Liu X, Gai Z, Tao F, Tang H, Xu P. Carotenoids play a positive role in the degradation of heterocycles by Sphingobium yanoikuyae. PLoS One. 2012; 7(6):e39522

62. Golestan Hashemi FS, Ismail MR, Rafii MY, Aslani F, Miah G, Muharam FM. Critical multifunctional role of the betaine aldehyde dehydrogenase gene in plants. Biotech Biotech Eq. 2018;32:815-29.

63. Maloney VJ, Park JY, Unda F, Mansfield SD. Sucrose phosphate synthase and sucrose phosphate phosphatase interact in planta and promote plant growth and biomass accumulation. J Exp Bot. 2015;66:4383-94.

64. Wang D, Liu H, Zhai G, Wang L, Shao J, Tao Y. OspTAC2 encodes a pentatricopeptide repeat protein and regulates rice chloroplast development. J Genet Genom. 2016;43:601-8. 
65. Fraudentali I, Ghuge SA, Carucci A, Tavladoraki P, Angelini R, RodriguesPousada RA, Cona A. Developmental, hormone-and stress-modulated expression profiles of four members of the Arabidopsis copper-amine oxidase gene family. Plant Physiol Biochem. 2020;147:141-60.

66. Gallogly MM, Mieyal JJ. Mechanisms of reversible protein glutathionylation in redox signaling and oxidative stress. Curr Opin Pharmacol. 2007;7:381-91.

67. Hayano T, Hirose M, Kikuchi M. Protein disulfide isomerase mutant lacking its isomerase activity accelerates folding in the cell. FEBS Lett. 1995;377:50511.

68. Kayum MA, Park JI, Nath UK, Saha G, Biswas MK, Kim HT, Nou IS. Genomewide characterization and expression profiling of PDI family gene reveals function as abiotic and biotic stress tolerance in Chinese cabbage (Brassica rapa ssp. pekinensis). BMC Genomics. 2017;18:885.

69. LV Y, Zhang S, Wang J, Hu Y. Quantitative proteomic analysis of wheat seeds during artificial ageing and priming using the isobaric tandem mass tag labeling. PLoS One. 2016;11(9):e0162851

70. Yang XB, Meng WL, Zhao MJ, Zhang AX, Liu W, Xu ZS, Wang YP, Ma J. Proteomics analysis to identify proteins and pathways associated with the novel lesion mimic mutant E40 in rice using iTRAQ-based strategy. Int J Mol Sci. 2019;20:1294.

71. Fazli IS, Abdin MZ, Jamal A, Ahmad S. Interactive effect of Sulphur and nitrogen on lipid accumulation, acetyl-CoA concentration and acetyl-CoA carboxylase activity in developing seeds of oilseed crops (Brassica compestris L. and Eruca sativa mill.). Plant Sci. 2005;168:29-36.

72. Liu W, Harrison DK, Chalupska D, Gornicki P, O'Donnell CC, Adkins SW, Haselkorn R, Williams RR. Single-site mutations in the carboxyltransferase domain of plastid acetyl-CoA carboxylase confer resistance to grass-specific herbicides. Proc Natl Acad Sci. 2007;104:3627-32.

73. Kanwischer M, Porfirova S, Bergmüller E, Dörmann P. Alterations in tocopherol cyclase activity in transgenic and mutant plants of Arabidopsis affect tocopherol content, tocopherol composition, and oxidative stress. Plant Physiol. 2005;137:713-23.

74. Liang D, Gao F, Ni Z, Lin L, Deng Q, Tang Y, Wang X, Luo X, Xia H. Melatonin improves heat tolerance in kiwifruit seedlings through promoting antioxidant enzymatic activity and glutathione S-transferase transcription. Molecules. 2018;23:584.

75. Zhao J, Qiu Z, Ruan B, Kang S, He L, Zhang S, et al. Functional inactivation of putative photosynthetic electron acceptor ferredoxin C2 ( $\mathrm{FdC2}$ ) induces delayed heading date and decreased photosynthetic rate in rice. PLoS One. 2015;10(11):e0143361.

76. Buchanan-Wollaston V, Earl S, Harrison E, Mathas E, Navabpour S, Page T, Pink D. The molecular analysis of leaf senescence - a genomics approach. Plant Biotech J. 2003;1:3-22.

77. Smith AM, Zeeman SC, Smith SM. Starch degradation. Annu Rev Plant Biol. 2005;56:73-98

78. Desclos M, Etienne P, Coquet L, Jouenne T, Bonnefoy J, Segura R, Reze S, Ourry A, Avice JC. A combined ${ }^{15} \mathrm{~N}$ tracing/proteomics study in Brassica napus reveals the chronology of proteomics events associated with $\mathrm{N}$ remobilisation during leaf senescence induced by nitrate limitation or starvation. Proteomics. 2009;9:3580-608.

79. Hollmann J, Gregersen PL, Krupinska K. Identification of predominant genes involved in regulation and execution of senescence-associated nitrogen remobilization in fag leaves of feld grown barley. J Exp Bot. 2014;65:396373.

80. Liu J, Wu YH, Yang JJ, Liu YD, Shen FF. Protein degradation and nitrogen remobilization during leaf senescence. J Plant Biol. 2008:51:11-9.

81. Moschen S, Luoni S, Rienzo JAD, et al. Integrating transcriptomic and metabolomic analysis to understand natural leaf senescence in sunfower. Plant Biotech J. 2016:14:719-34.

82. Carrión CA, Costa ML, Martínez DE, Mohr C, Humbeck K, Guiamet JJ. In vivo inhibition of cysteine proteases provides evidence for the involvement of 'senescence-associated vacuoles' in chloroplast protein degradation during dark-induced senescence of tobacco leaves. J Exp Bot. 2013;64:4967-80.

83. Drake R, John I, Farrell A, Cooper W, Schuch W, Grierson D. Isolation and analysis of cDNAs encoding tomato cysteine proteases expressed during leaf senescence. Plant Mol Biol. 1996;30:755-67.

84. Li G, Pan J, Cui K, Yuan M, Hu Q, Wang W, Mohapatra PK, Nie L, Huang J, Peng S. Limitation of unloading in the developing grains is a possible cause responsible for low stem non-structural carbohydrate translocation and poor grain yield formation in rice through verification of recombinant inbred lines. Front Plant Sci. 2017:8:1369.
85. Li W, Zhang H, Li X, Zhang F, Liu C, Du Y, Gao X, Zhang Z, Zhang X, Hou Z, Zhou H, Sheng X, Wang G, Guo Y. Intergrative metabolomic and transcriptomic analyses unveil nutrient remobilization events in leaf senescence of tobacco. Sci Rep. 2017;7:12126.

86. Li Z, Wang F, Lin W, Zhao Q, Liu J, Cheng F. Carbon reserve and remobilization in leaf sheaths during the grain-filling stage in response to leaf early senescence. Acta Physiol Plant. 2017;39:10.

87. Gregersen PL, Culetic A, Boschian L, Krupinska K. Plant senescence and crop productivity. Plant Mol Biol. 2013;82:603-22.

88. Noodén LD, Guiamét JJ, John I. Senescence mechanisms. Physiol Plant. 1997:101:746-53.

89. Roberts IN, Caputo C, Kade M, Criado MV, Barneix AJ. Subtilisin-like serine proteases involved in $\mathrm{N}$ remobilization during grain filling in wheat. Acta Physiol Plant. 2011;33:1997-2001.

90. Kong L, Wang F, Feng B, Li S, Si J, Zhang B. The structural and photosynthetic characteristics of the exposed peduncle of wheat (Triticum aestivum L.): an important photosynthate source for grain-filling. BMC Plant Biol. 2010;10:141.

91. Xu N, Dong M, Yang Y, Wang Y, Chang Y, Wan J, Zhu W, Wang J, Liu W. Integrative transcriptomics, proteomics, and metabolomics data analysis exploring the injury mechanism of ricin on human lung epithelial cells. Toxicol in Vitro. 2019;60:160-72.

92. Xiong Q, Zhong L, Shen T, Cao C, He H, Chen X. iTRAQ-based quantitative proteomic and physiological analysis of the response to $\mathrm{N}$ deficiency and the compensation effect in rice. BMC Genomics. 2019;20:681.

\section{Publisher's Note}

Springer Nature remains neutral with regard to jurisdictional claims in published maps and institutional affiliations.
Ready to submit your research? Choose BMC and benefit from:

- fast, convenient online submission

- thorough peer review by experienced researchers in your field

- rapid publication on acceptance

- support for research data, including large and complex data types

- gold Open Access which fosters wider collaboration and increased citations

- maximum visibility for your research: over $100 \mathrm{M}$ website views per year

At BMC, research is always in progress.

Learn more biomedcentral.com/submissions 